Supporting Information

\title{
Determining Enantiomeric Excess and Absolute Configuration of In situ Fluorine-Labeled Amines and Alcohols by ${ }^{19} \mathrm{~F}$ NMR Spectroscopy
}

Sumin Jang, Hahyoun Park, Quynh Huong Duong, Eun-Jeong Kwahk, and Hyunwoo Kim*

Department of Chemistry, Korea Advanced Institute of Science and Technology (KAIST), Daejeon 34141, Republic of Korea

\section{Table of contents}

1 General information

S-2

2 Chiral solvation with increasing ratios of [Co]BArF S-3

3 Comparison between HPLC and ${ }^{19} \mathrm{~F}$ NMR data S-4

$4 \quad$ Chiral ${ }^{19} \mathrm{~F}$ NMR analysis of in situ fluorinated analytes S-7

5 Determination of absolute configuration S-18

6 Analysis of L-menthol and neomenthol S-19

7 Fluorine-labeling with 2-fluorobenzoyl chloride or trifluoroacetyl S-19 anhydride 


\section{General information}

Commercially available compounds were used without further purification or drying. The ${ }^{1} \mathrm{H}$ and ${ }^{19} \mathrm{~F}$ NMR spectra were recorded on a Bruker Ascend 400 spectrometer $\left(400 \mathrm{MHz}\right.$ for ${ }^{1} \mathrm{H}$ and $376 \mathrm{MHz}$ for ${ }^{19} \mathrm{~F} \mathrm{NMR}$ ) and are reported in ppm, relative to residual protonated solvent peak for ${ }^{1} \mathrm{H} N M R$ and referenced with $\mathrm{CF}_{3} \mathrm{CO}_{2} \mathrm{H}(-76.55 \mathrm{ppm})$ externally. For ${ }^{19} \mathrm{~F}$ NMR, a default relaxation delay (D1) of $1 \mathrm{~s}$ was adopted and pulse angle of $90^{\circ}$ was used to provide maximum signal-to-noise ( $\left.\mathrm{S} / \mathrm{N}\right)$. 64 scans were collected over a spectral width of typically $-70-230 \mathrm{ppm}$. The Bruker pulse program, zgfhiggn (inverse-gated ${ }^{1} \mathrm{H}$ decoupled pulse sequence), was used with a receiver gain (RG) of 203. [Co]PF 6 was synthesized with $(R, R)$-S1 and (S,S)-1,2-diphenyl ethylene diamine (dpen) according to the previous report (Org. Lett. 2020, 22, 4185-4189). Ent-[Co]PF 6 was synthesized with $(S, S)$-S1 and $(R, R)-1,2-d p e n$

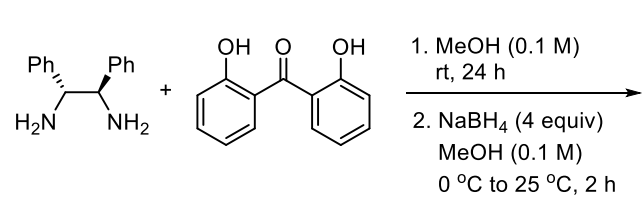

$(R, R)$-dpen

$0^{\circ} \mathrm{C}$ to $25^{\circ} \mathrm{C}, 2 \mathrm{~h}$

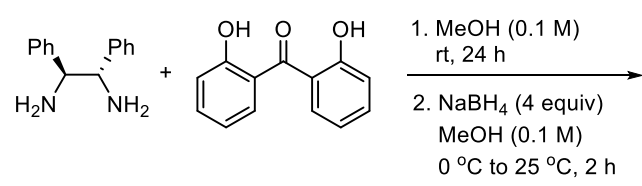

$(S, S)$-dpen

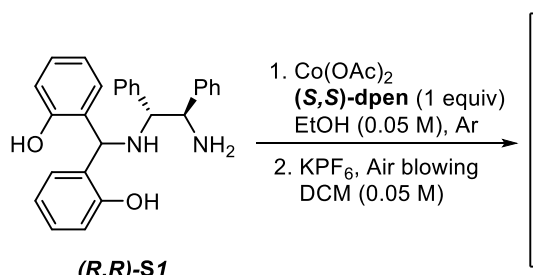

$(R, R)-\mathrm{S} 1$

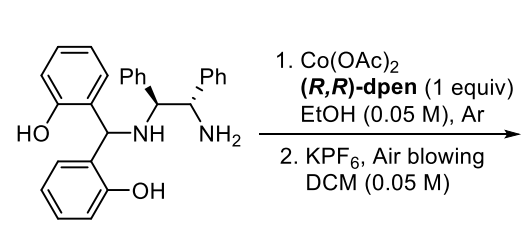

$(S, S)-S 1$

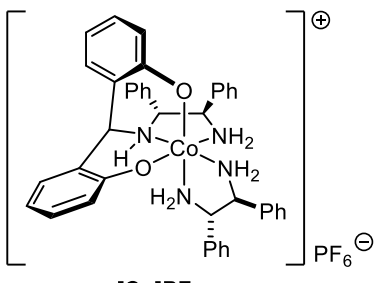

$\left[\mathrm{Co}_{\mathrm{PF}}\right.$

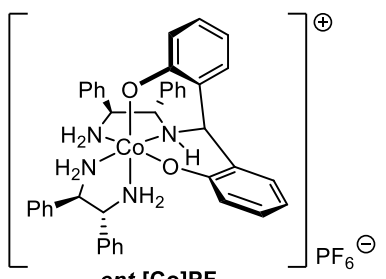

Figure S1. Synthesis of $\left[\mathrm{Co}_{\mathrm{P}}\right] \mathrm{P} 6$ and ent-[Co]PF 6

\section{General procedure for chiral solvation of in situ fluorinated compounds.}

\section{Preparation of [Co]BArF (0.1 M) stock solution}

[Co]PF $6(0.1 \mathrm{mmol}, 82.4 \mathrm{mg})$ was dissolved in $0.8 \mathrm{~mL}$ of $\mathrm{CDCl}_{3}$ in a $1 \mathrm{~mL}$ volumetric flask. To the solution, NaBArF $(0.1 \mathrm{mmol}, 88.6 \mathrm{mg})$ was added and sonicated for 10 minutes. $\mathrm{CDCl}_{3}$ was added to the line marked on the volumetric flask, so the total volume can be $1 \mathrm{~mL}$. Precipitated $\mathrm{NaPF}_{6}$ was filtered by a syringe. ${ }^{19} \mathrm{~F}$ NMR analysis indicated that $\mathrm{BArF}^{-}$was replaced with $\mathrm{PF}_{6}-$ in a range of $86 \%-100 \%$.

\section{Method A. Chiral analysis of amines and amino alcohols}

In a $5 \mathrm{~mm}$ NMR tube, rac-1-phenylethylamine $(0.01 \mathrm{mmol}, 1.2 \mathrm{mg})$ was dissolved in $0.1 \mathrm{~mL}$ of $\mathrm{CDCl}_{3}$. 2-fluorobenzoyl chloride $(0.015 \mathrm{mmol}, 2.4 \mathrm{mg})$ was added to the solution and sonicated for 10 minutes. After that, $0.1 \mathrm{~mL}$ of [Co]BArF $\left(0.1 \mathrm{M}\right.$ in $\left.\mathrm{CDCl}_{3}\right)$ stock solution and $0.4 \mathrm{~mL}$ of $\mathrm{CDCl}_{3}$ was added. ${ }^{19} \mathrm{~F} \mathrm{NMR}$ spectra $(376 \mathrm{MHz}$ ) was taken of the solution (ca. $\mathrm{c}=16.7 \mathrm{mM}$ ). For the determination of $R / S$ configuration, enantiopure or enantioenriched samples can be analyzed. 


\section{Method B. Chiral analysis of alcohols}

In a $5 \mathrm{~mm}$ NMR tube, rac-1-phenylethanol $(0.01 \mathrm{mmol}, 1.2 \mathrm{mg})$ was dissolved in $0.1 \mathrm{~mL}$ of $\mathrm{CDCl}_{3}$. Tetramethylethylenediamine $(1.74 \mathrm{mg})$ and 2-fluorobenzoyl chloride $(0.015 \mathrm{mmol}, 2.4 \mathrm{mg})$ was added to the solution and sonicated for 10 minutes. After that, $0.1 \mathrm{~mL}$ of [Co]BArF $\left(0.1 \mathrm{M}\right.$ in $\left.\mathrm{CDCl}_{3}\right)$ stock solution and $0.4 \mathrm{~mL}$ of $\mathrm{CDCl}_{3}$ was added. ${ }^{19} \mathrm{~F} \mathrm{NMR}$ spectra $(376 \mathrm{MHz}$ ) was taken of the solution (ca. $\mathrm{C}$ $=16.7 \mathrm{mM}$ ). For the determination of $R / S$ configuration, enantiopure or enantioenriched samples can be analyzed.

\section{Chiral solvation with increasing ratios of [Co]BArF}

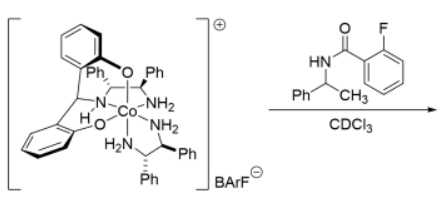

(a)

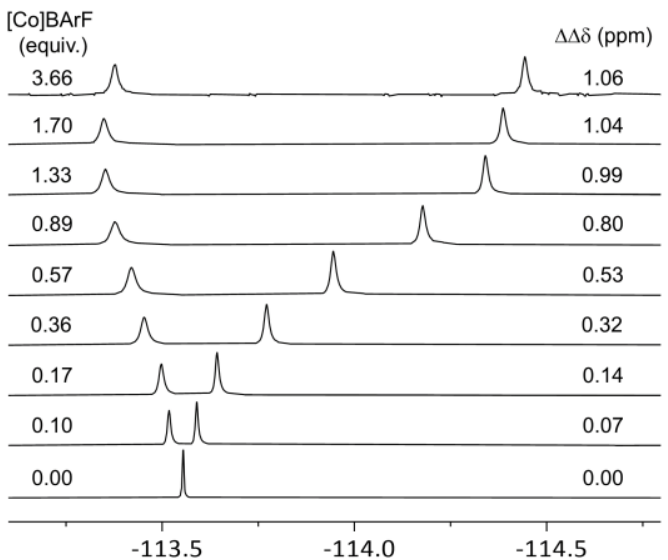

(b)

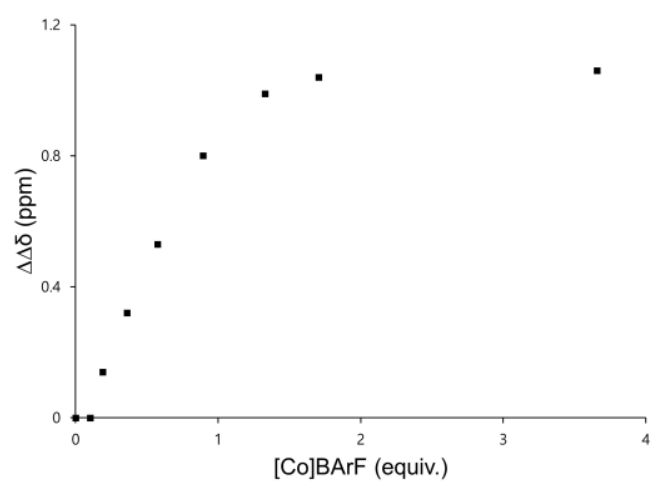

Figure S2. (a) Partial ${ }^{19} \mathrm{~F}$ NMR spectra of rac-2-fluoro- $N$-(1-phenylethyl)benzamide with varied equivalents of [Co]BArF ( $\mathrm{C}_{\text {tot }}=33.3 \mathrm{mM}$ in $\mathrm{CDCl}_{3}$, equiv = equivalent of [Co]BArF) and (b) a plot of $\Delta \Delta \delta$ of fluorine peaks versus equivalent of [Co]BArF 


\section{Comparison between HPLC and ${ }^{19} \mathrm{~F}$ NMR data}

\section{a. Isolated analyte analysis}

HPLC: 2-Fluoro- $N$-(1-phenylethyl)benzamide samples of varying \% ee were directly analyzed by HPLC with chiral columns (Chiralpak IB Hexane: IPA= 95: 5 flow rate $=1 \mathrm{~mL} / \mathrm{min}$ ).

${ }^{19} \mathrm{~F}$ NMR: 2-Fluoro- $\mathrm{N}$-(1-phenylethyl)benzamide samples of varying $\%$ ee were mixed with [Co]BArF and ${ }^{19} \mathrm{~F}$ NMR spectra were taken (ca. $\mathrm{c}=16.7 \mathrm{mM}$, Inverse-gated decoupling, D1 $=5 \mathrm{~s}, \mathrm{SW}=237 \mathrm{ppm}$, $\mathrm{O} 1 \mathrm{P}=-120 \mathrm{ppm}$, number of scan $=64)$.

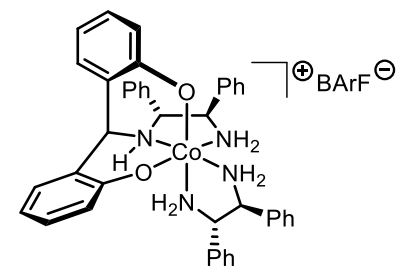

HPLC

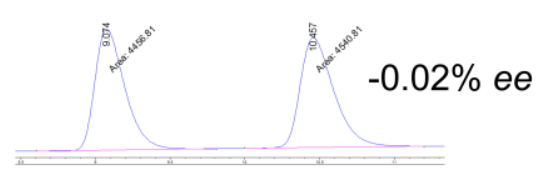

$19.76 \%$ ee

$29.26 \%$ ee

$39.65 \%$ ee

$59.28 \%$ ee

$79.22 \%$ ee
NMR
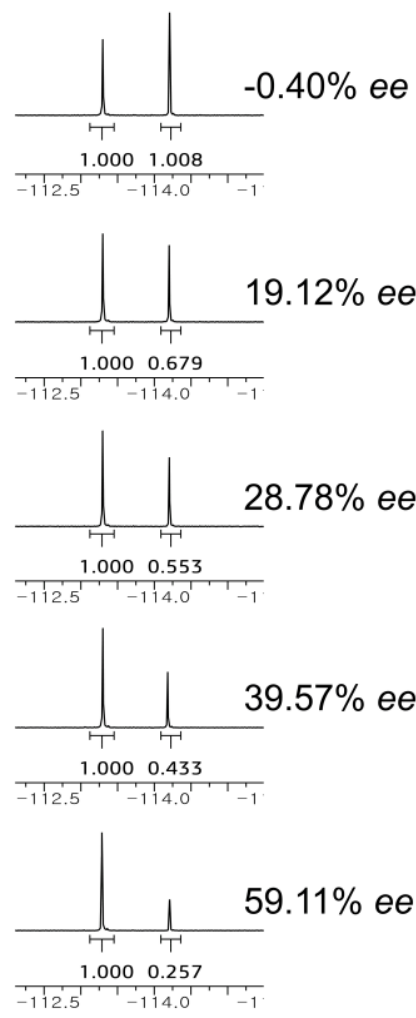

$80.18 \%$ ee

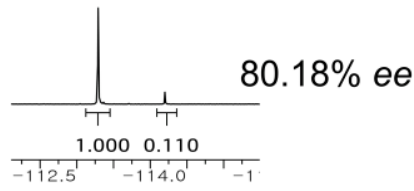




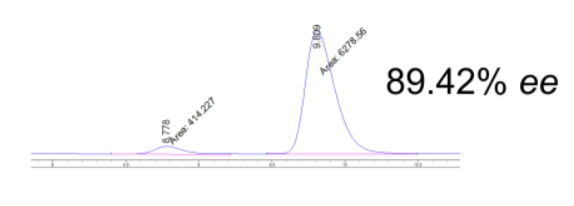

$98.94 \%$ ee
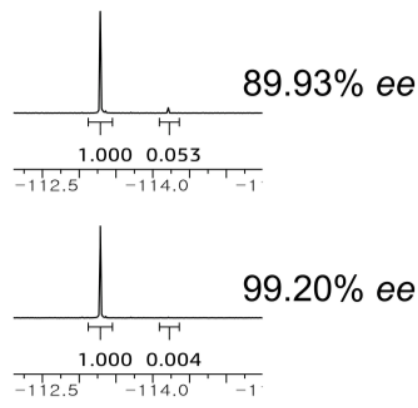

Figure S3. Partial HPLC chromatograms and ${ }^{19} \mathrm{~F}\left\{{ }^{1} \mathrm{H}\right\}$ NMR spectra of 2-Fluoro- $N$-(1-phenylethyl) benzamide with varying $\%$ ee.

\section{b. In situ fluorinated analyte analysis}

HPLC: 1-Phenylethylamine samples of varying \% ee were mixed with 2-flruorobenzoyl chloride (2 equiv) and sonicated for $10 \mathrm{~min}$. The samples were then analyzed by HPLC with chiral columns (Chiralpak IB Hexane:IPA $=95: 5$ flow rate $=1 \mathrm{~mL} / \mathrm{min}$ ).

${ }^{19} \mathrm{~F}$ NMR: 1-Phenylethylamine samples of varying $\%$ ee were mixed with 2-flruorobenzoyl chloride (2 equiv) and sonicated for $10 \mathrm{~min}$. The samples were then mixed with [Co]BArF and ${ }^{19} \mathrm{~F}$ NMR spectra were taken (Inverse-gated decoupling, D1 $=5 \mathrm{~s}, \mathrm{SW}=237 \mathrm{ppm}, \mathrm{O} 1 \mathrm{P}=-120 \mathrm{ppm}$, number of scan = $64)$.

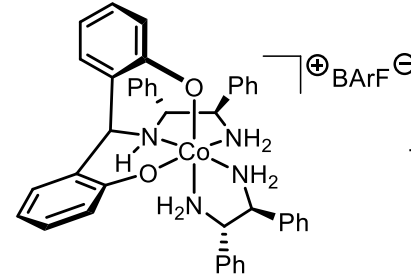

HPLC

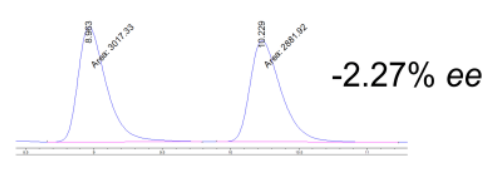

$20.27 \%$ ee

$39.11 \%$ ee<smiles>C[C+](N)c1ccccc1</smiles><smiles>O=C(Cl)c1ccccc1F</smiles>
$\overrightarrow{\mathrm{CDCl}_{3}(0.5 \mathrm{~mL})}$ NMR

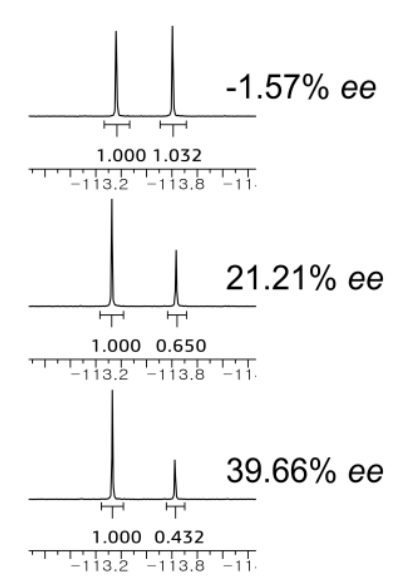



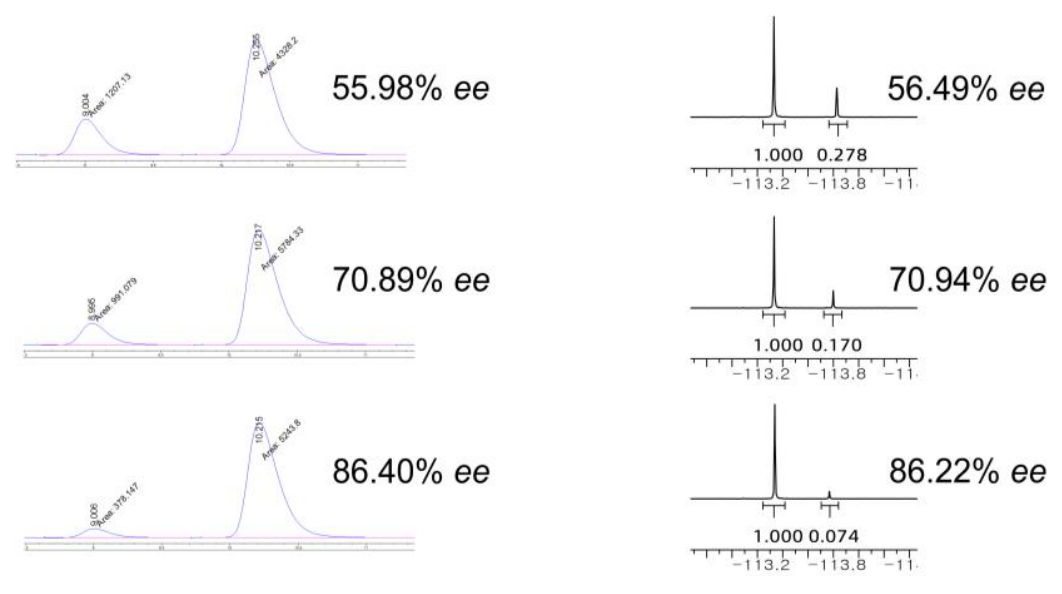

$92.66 \%$ ee

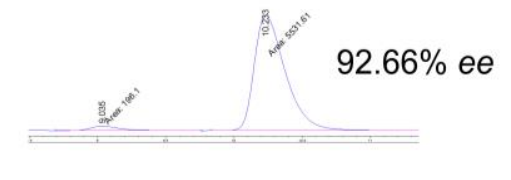

$99.50 \%$ ee
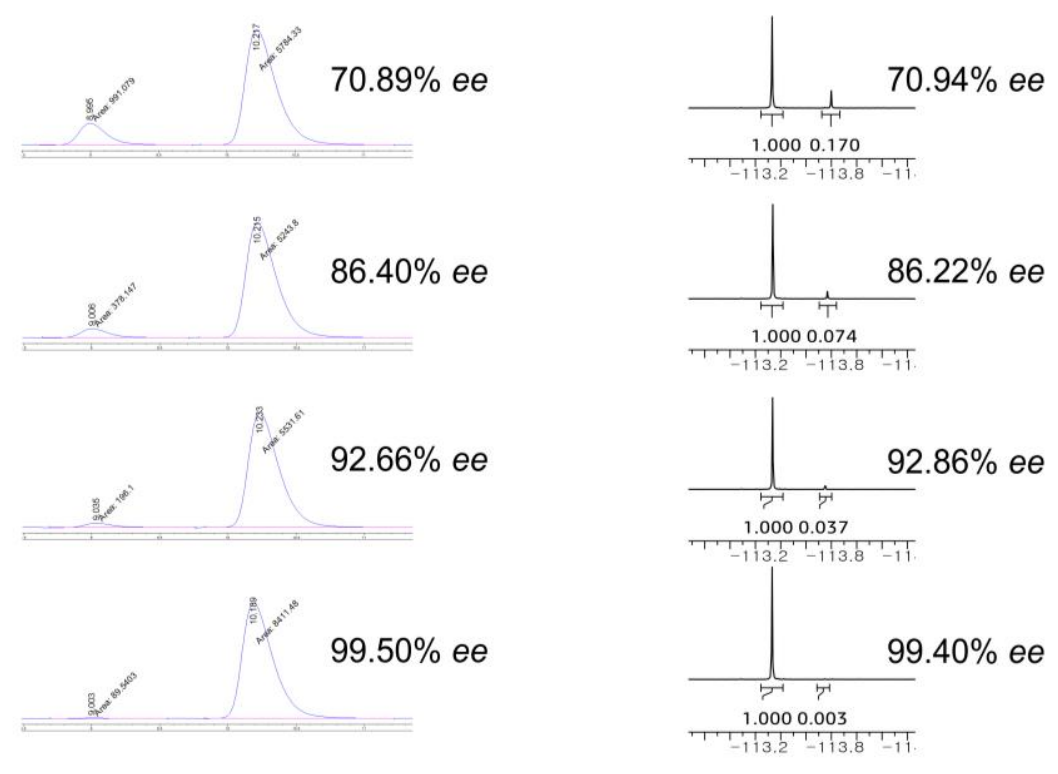

Figure S4. Partial HPLC chromatograms and ${ }^{19} \mathrm{~F}\left\{{ }^{1} \mathrm{H}\right\}$ NMR spectra of in situ fluorinated 1phenylethylamine with varying $\%$ ee.

(a) Isolated analyte

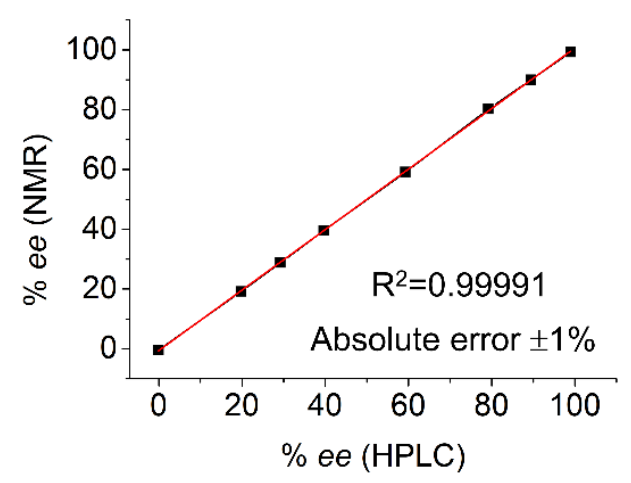

(b) In situ fluorinated analyte

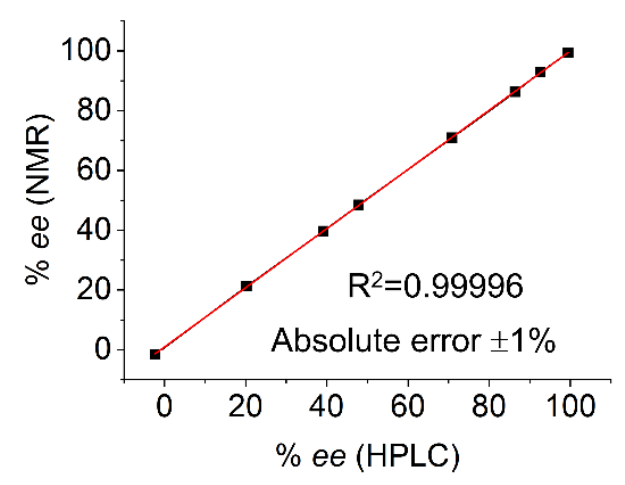

Figure S5. A linear plot between HPLC $\%$ ee and NMR $\%$ ee of (a) isolated analyte and (b) in situ fluorinated analyte. 


\section{Chiral ${ }^{19} \mathrm{~F}$ NMR analysis of in situ fluorinated analytes}

(a)

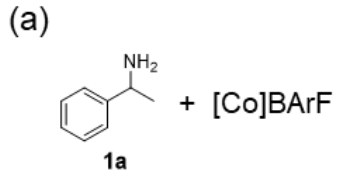

rac
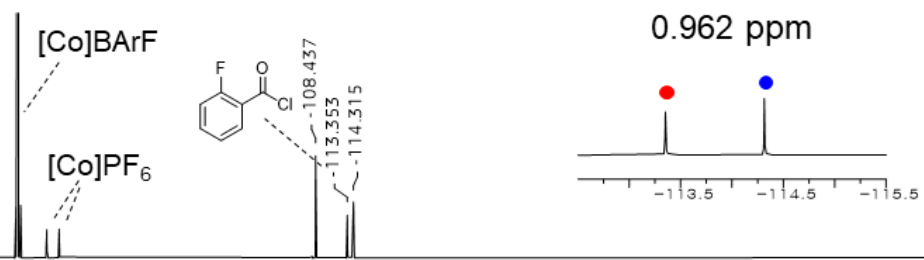

$(R):(S)=25.2: 74.8$

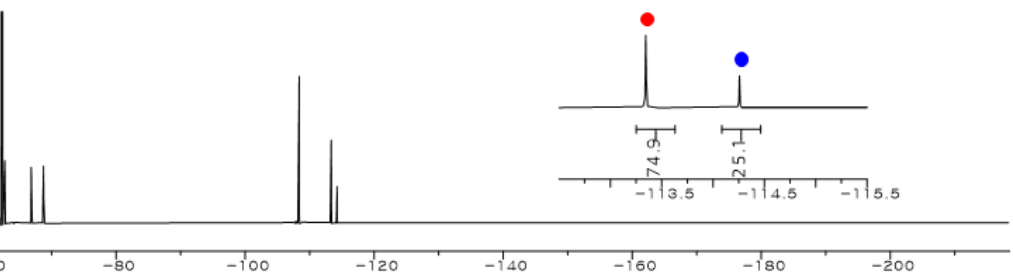

(b)
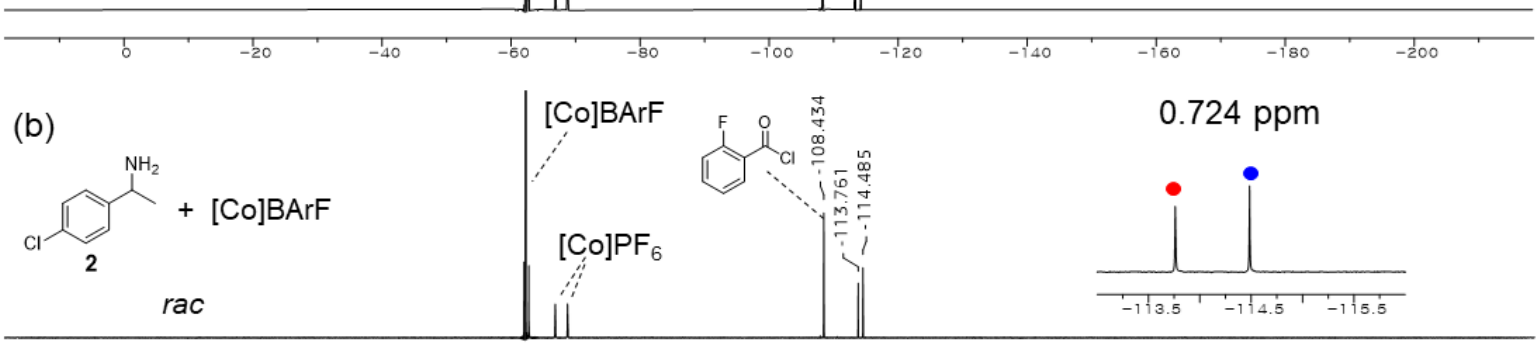

0.724 ppm
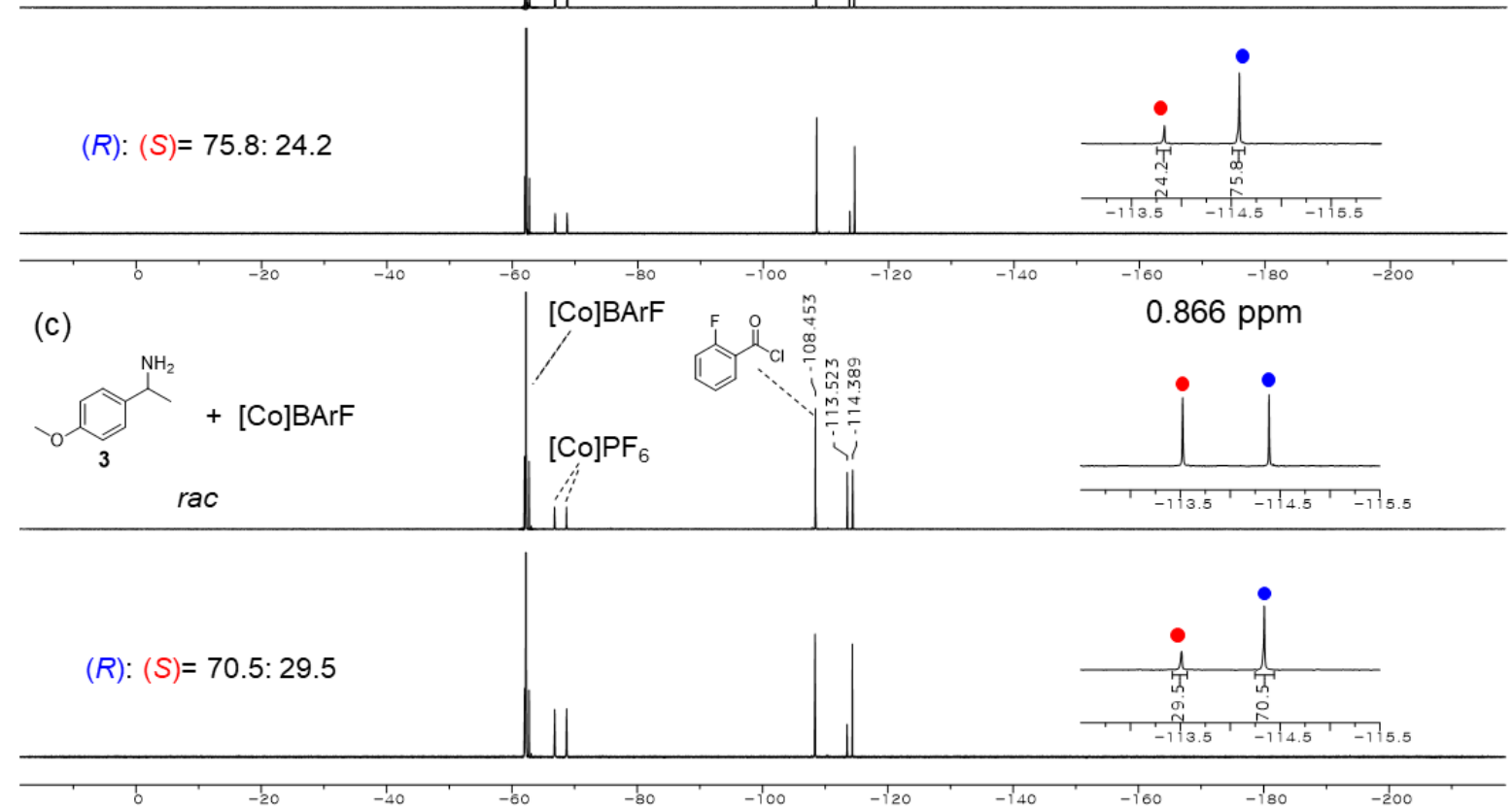

(d)
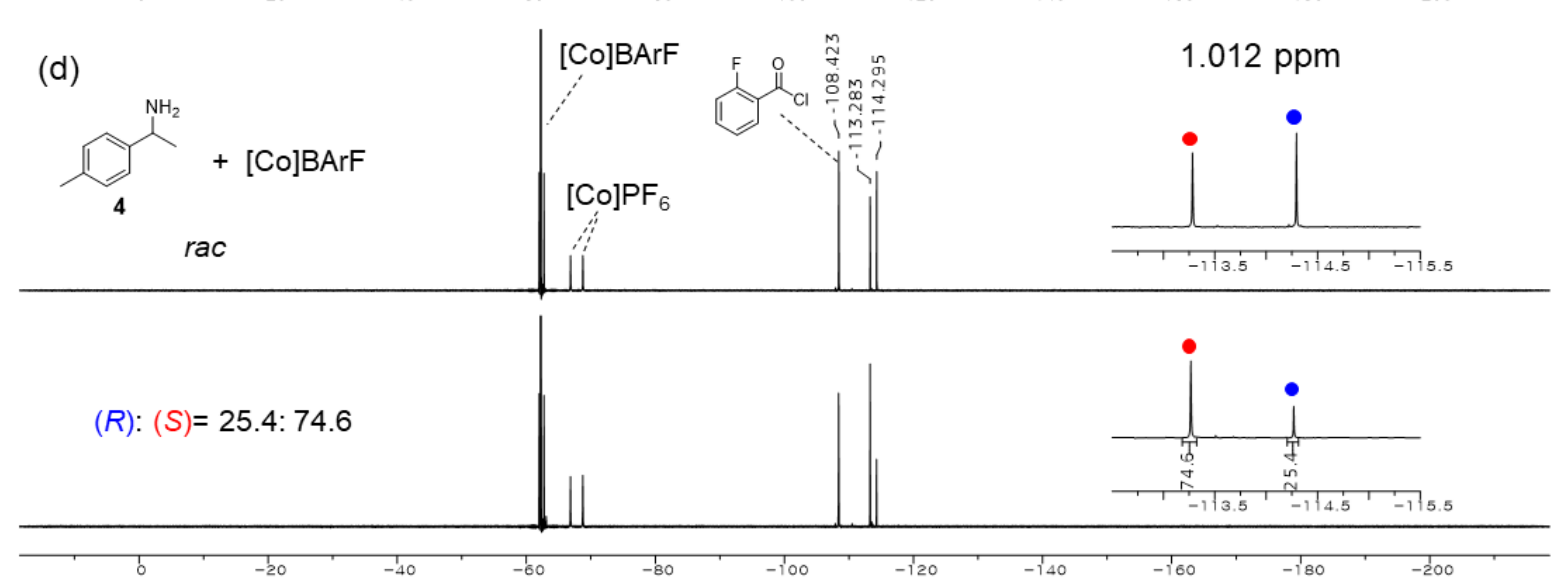

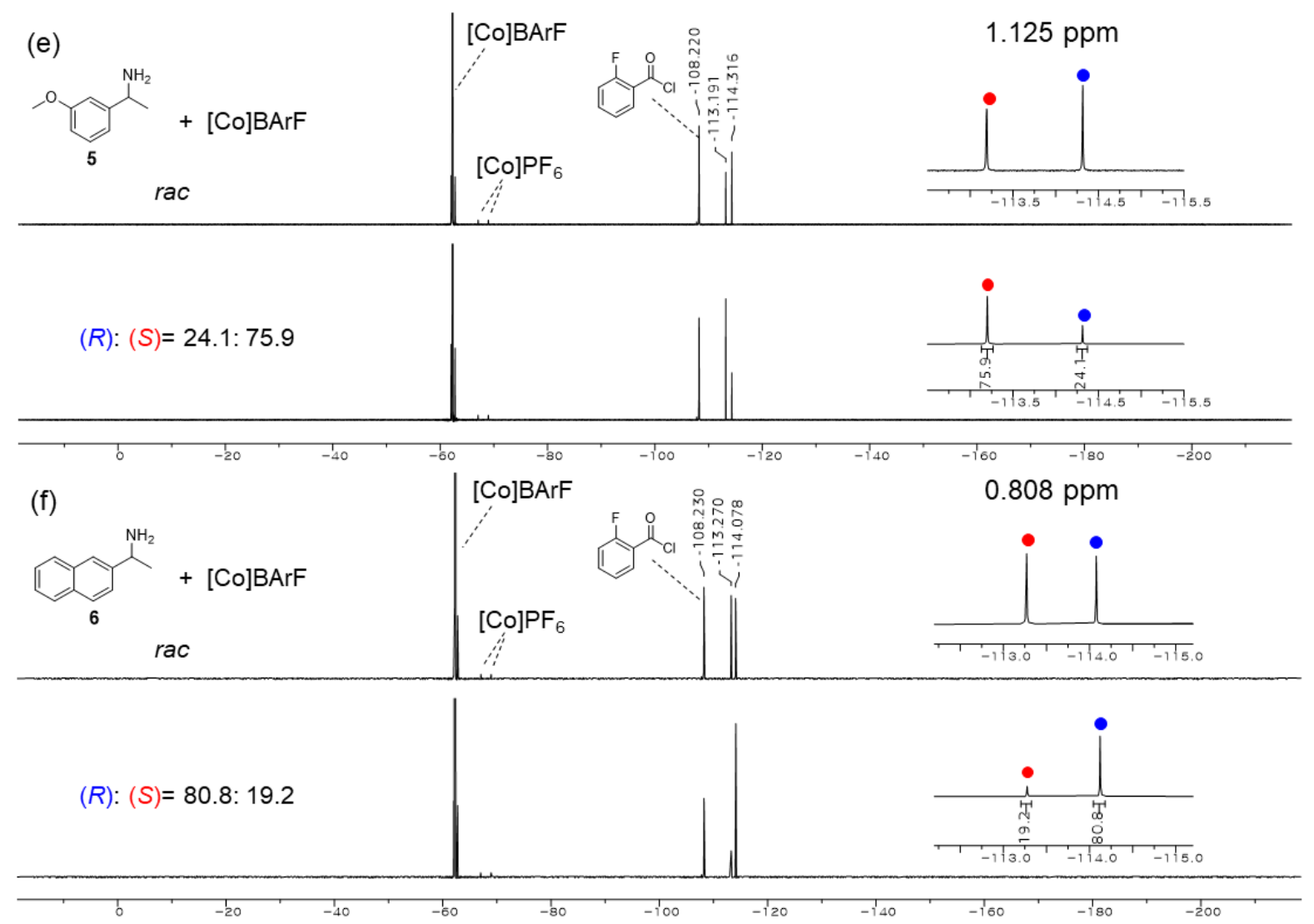

(g)
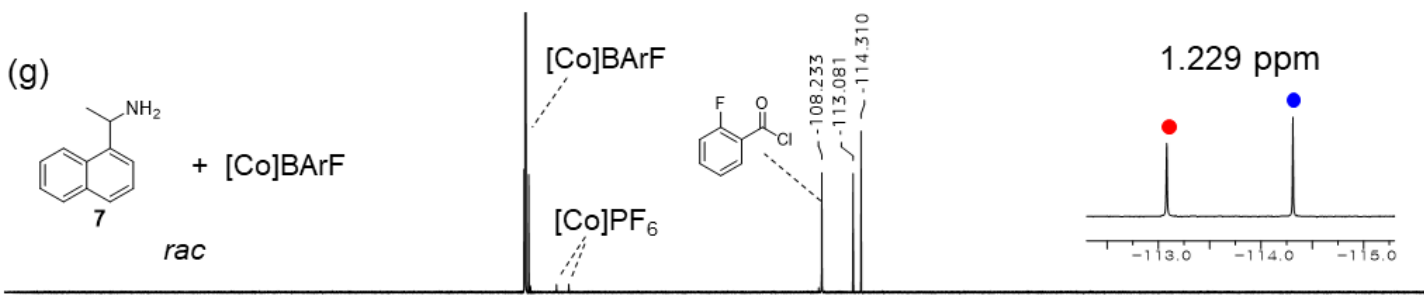

$(R):(S)=75.9: 24.1$

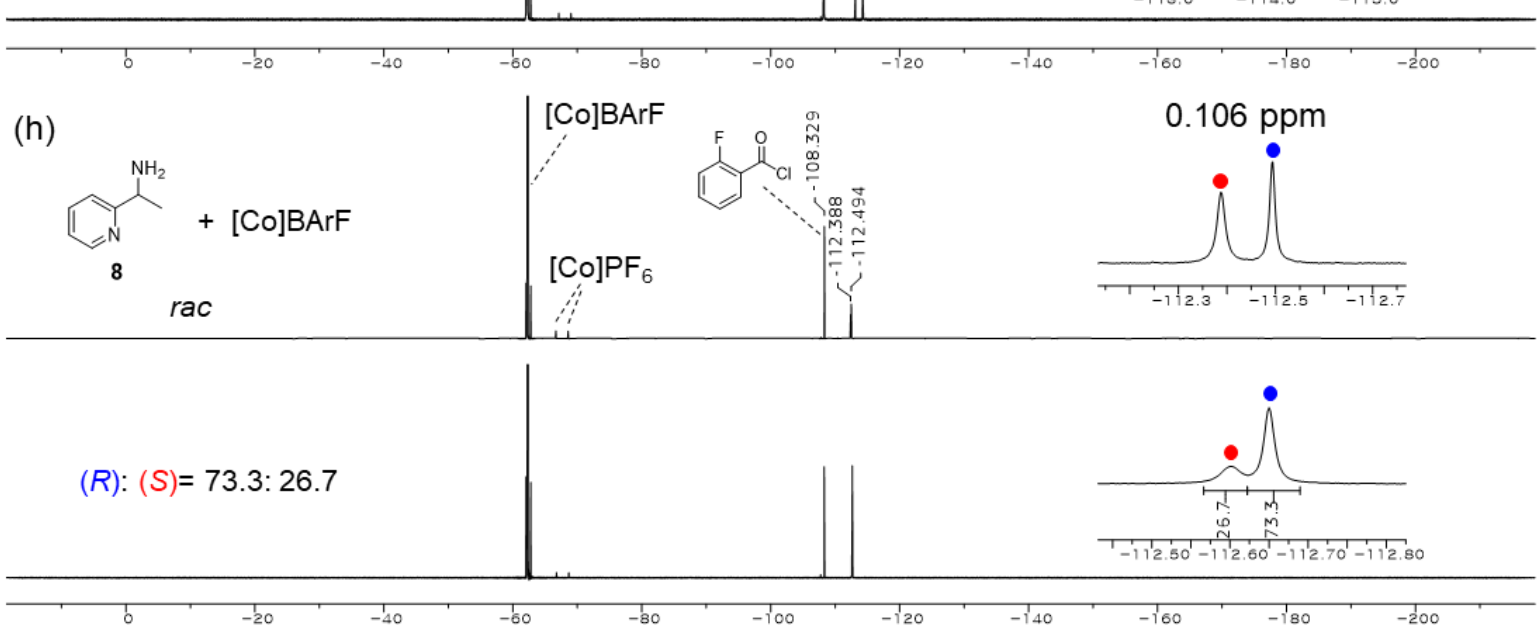



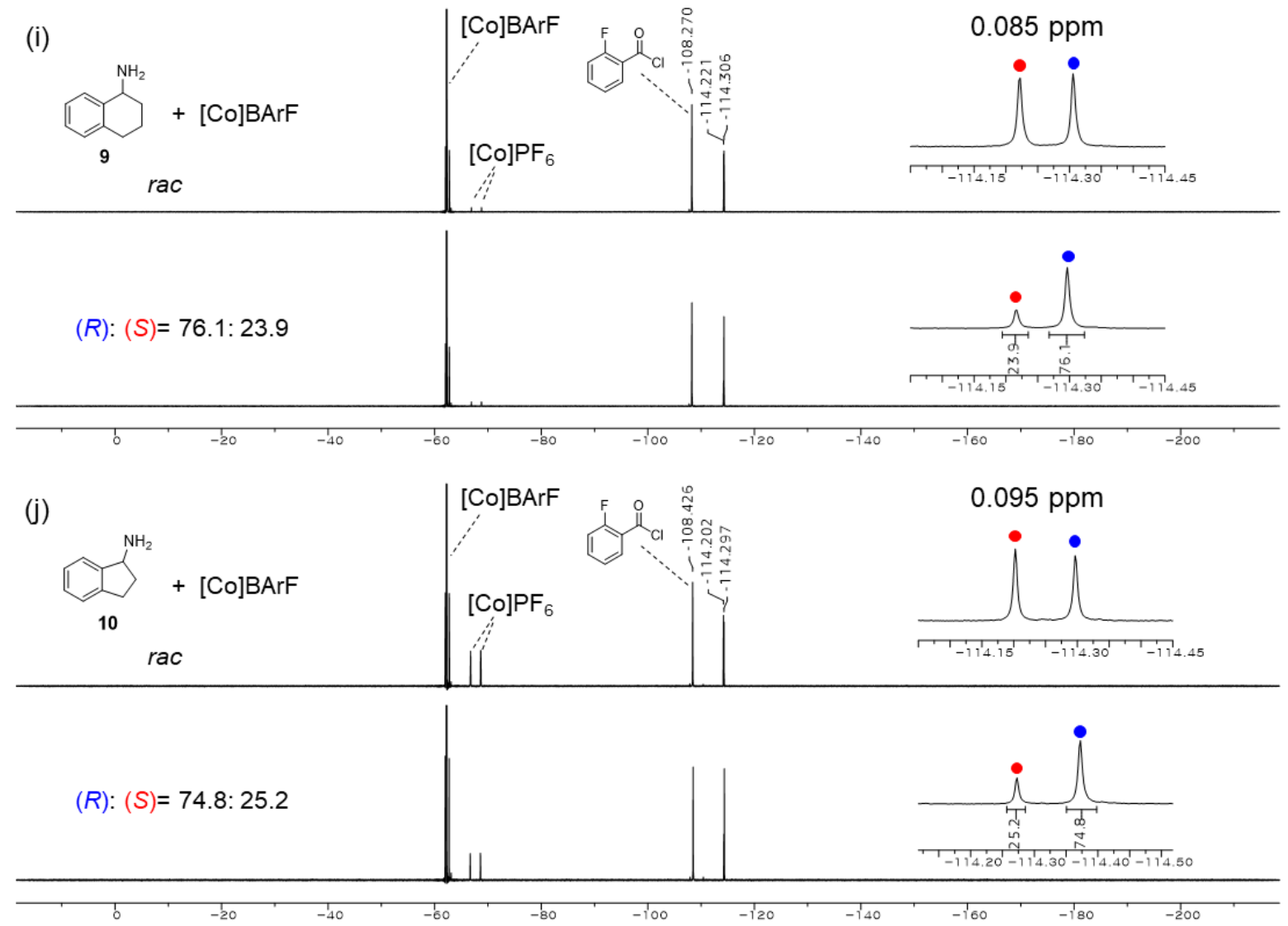

(k)

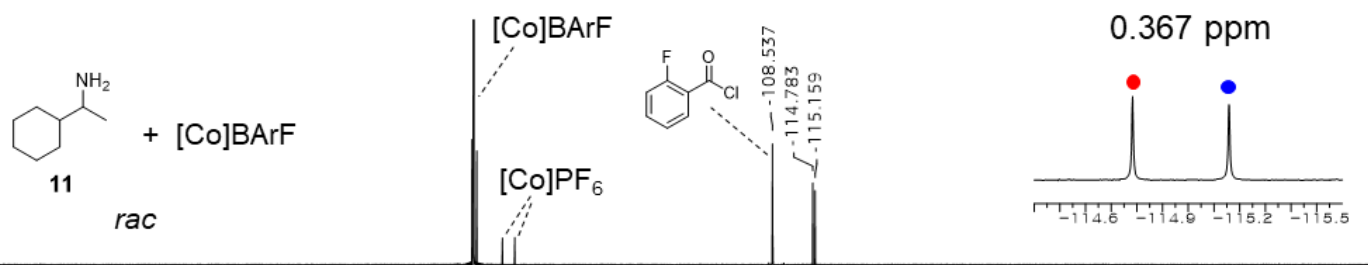

$(R):(S)=74.4: 25.6$

(I)
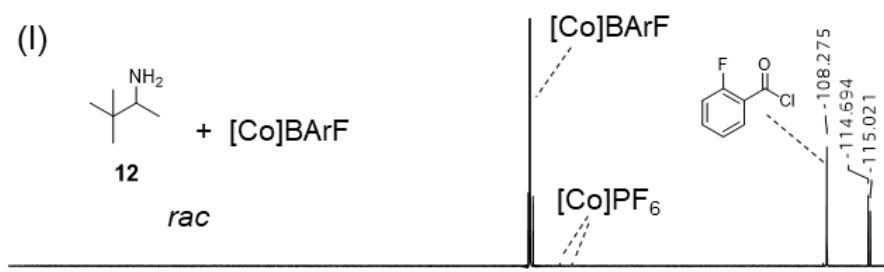

$0.327 \mathrm{ppm}$

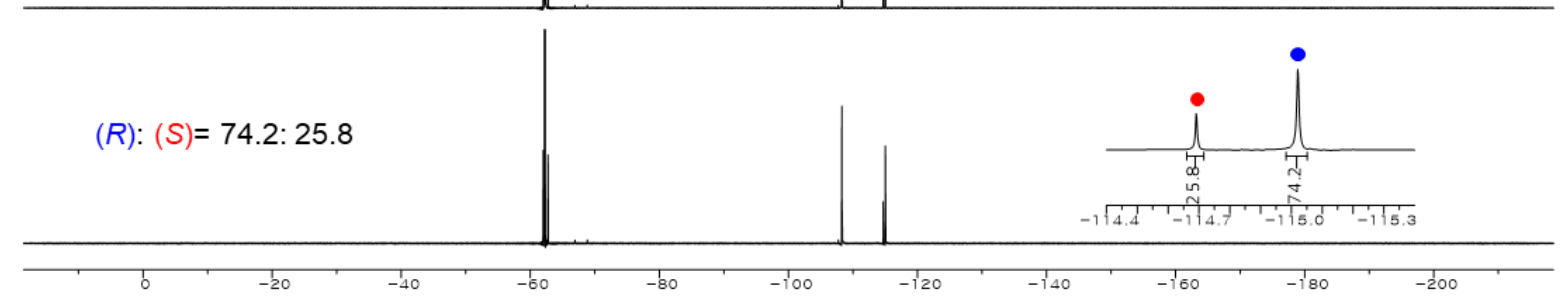




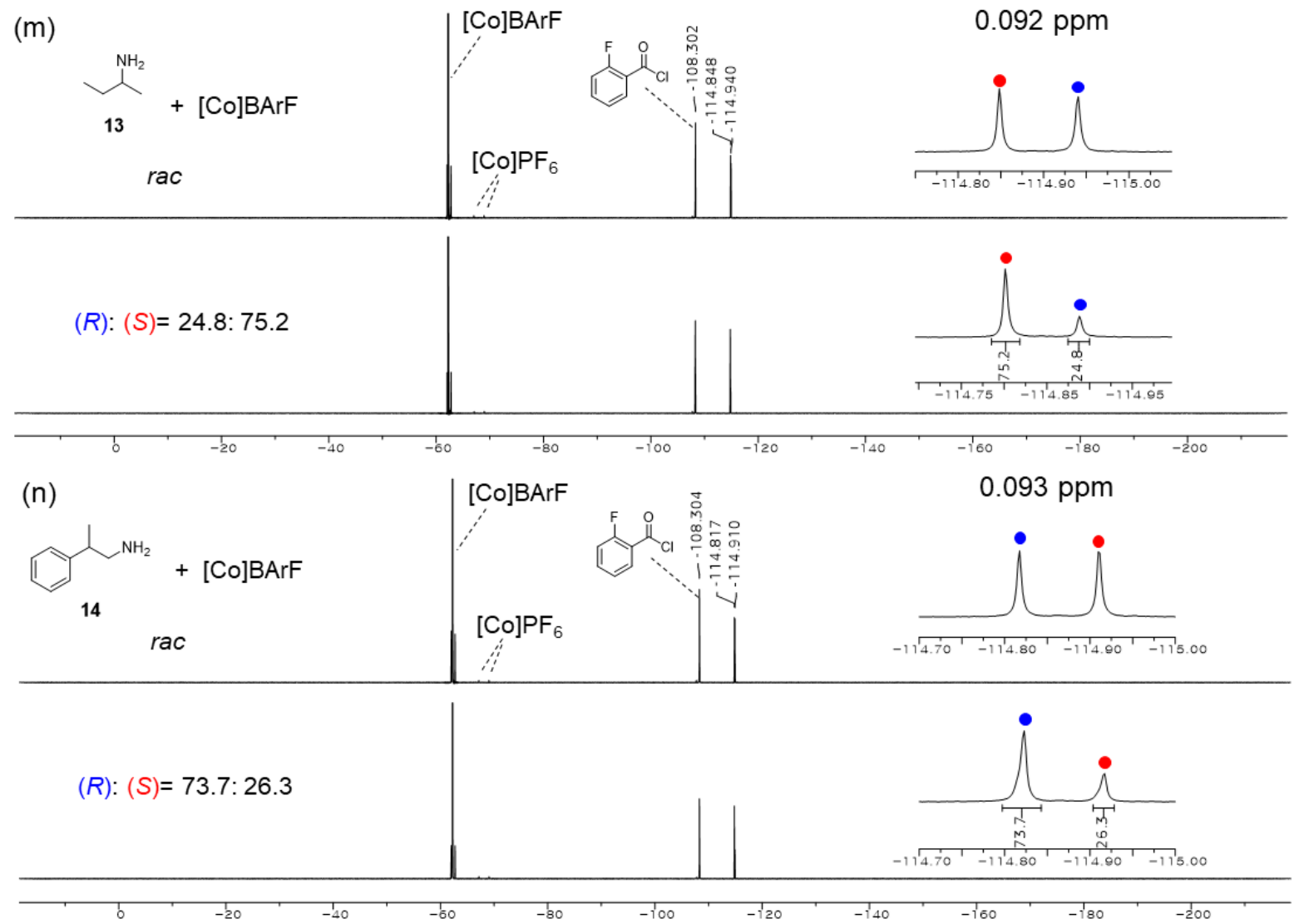

(0)
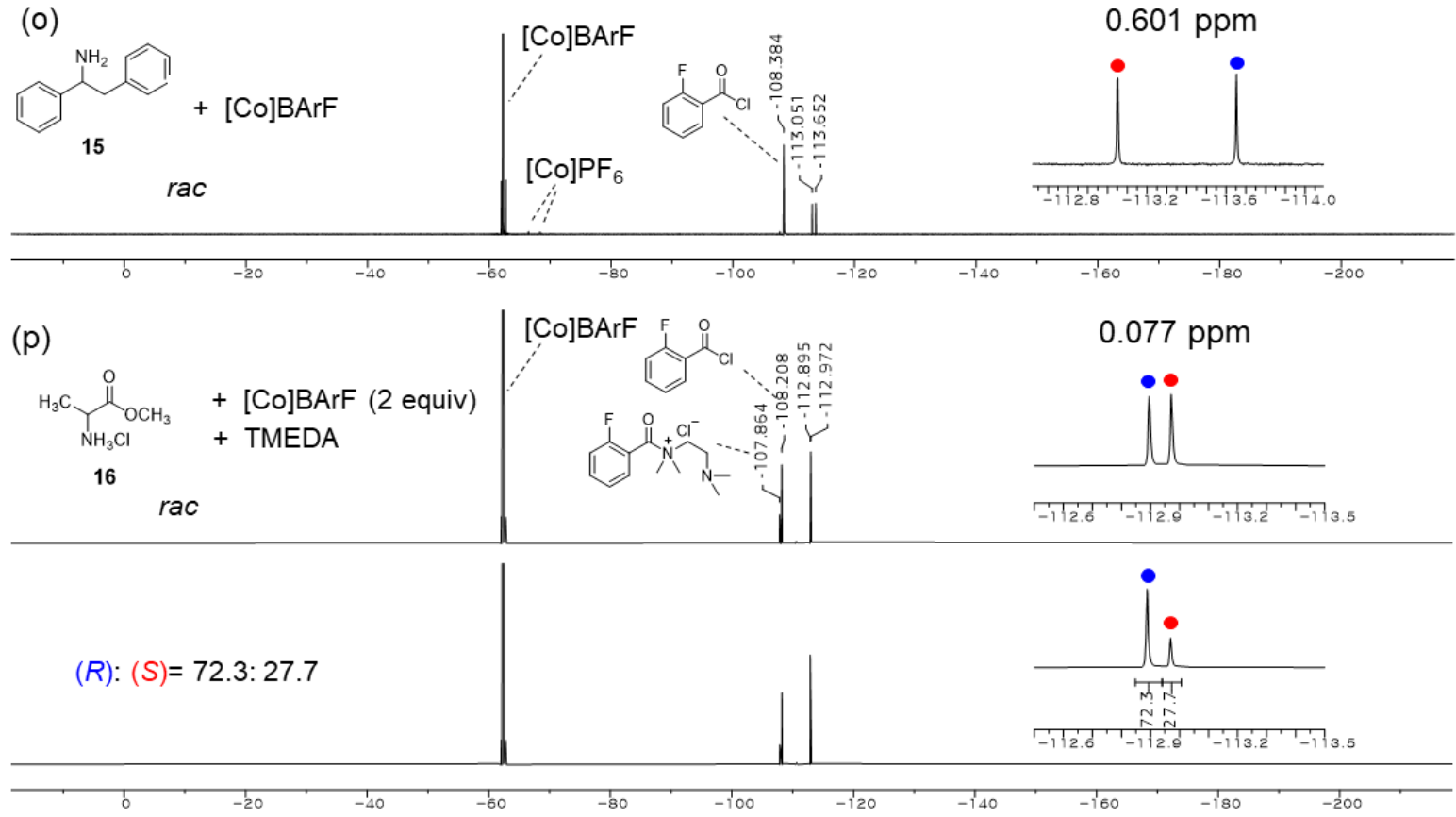

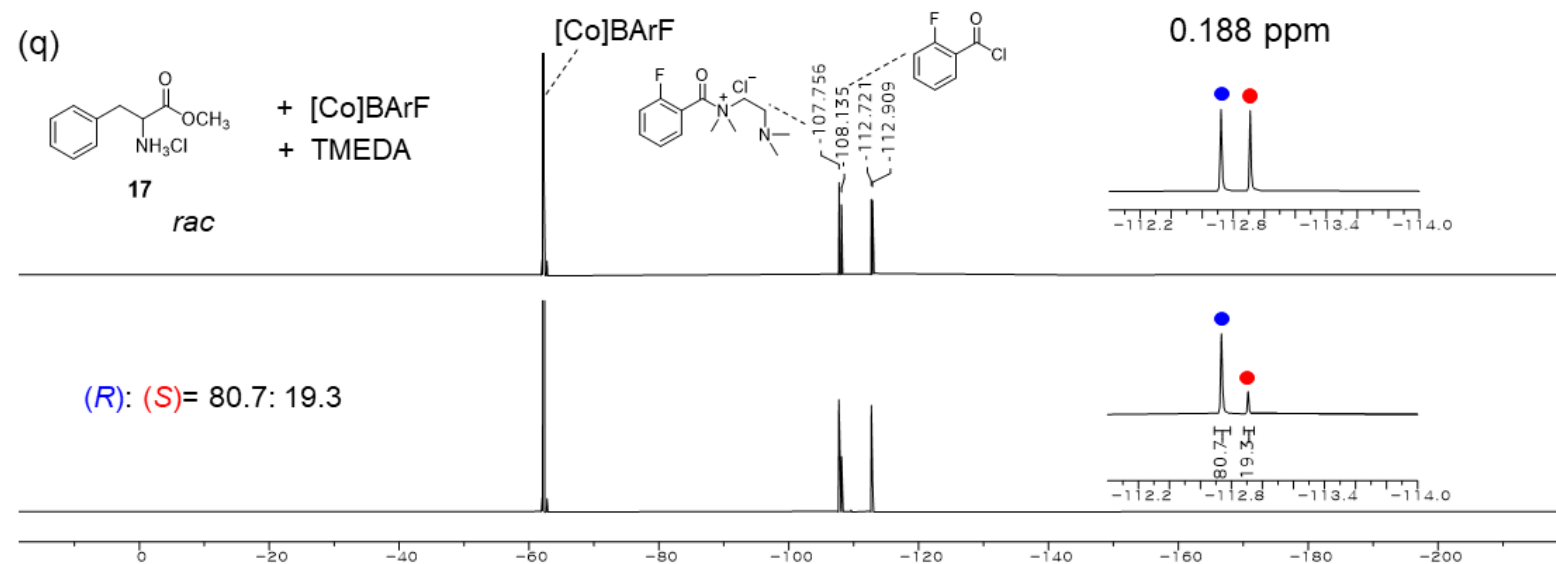

(r)

$\overbrace{18}^{\mathrm{NH}_{2}} \mathrm{OH}+[\mathrm{Co}] \mathrm{BArF}$

[Co]BArF

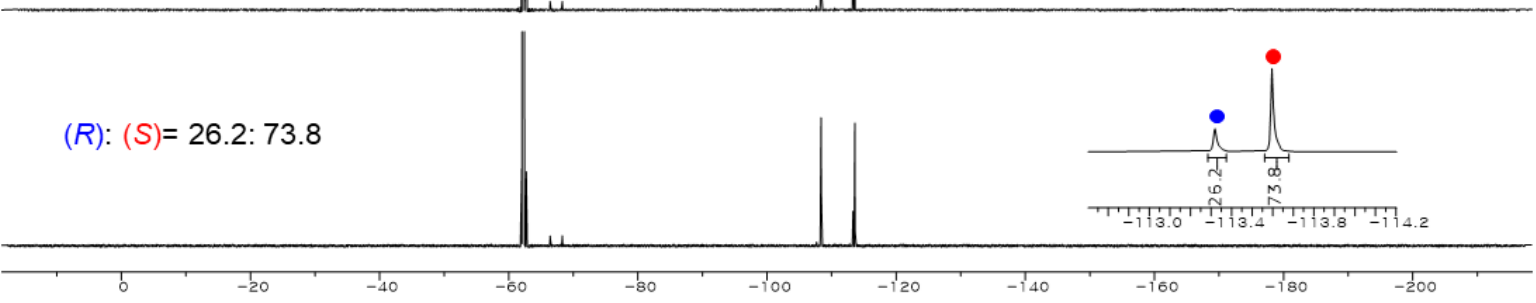

(s)
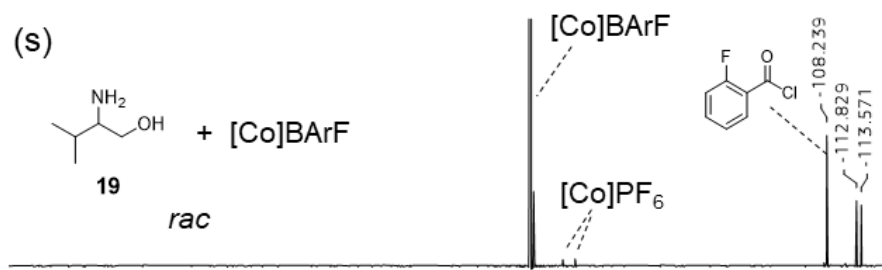

$0.279 \mathrm{ppm}$
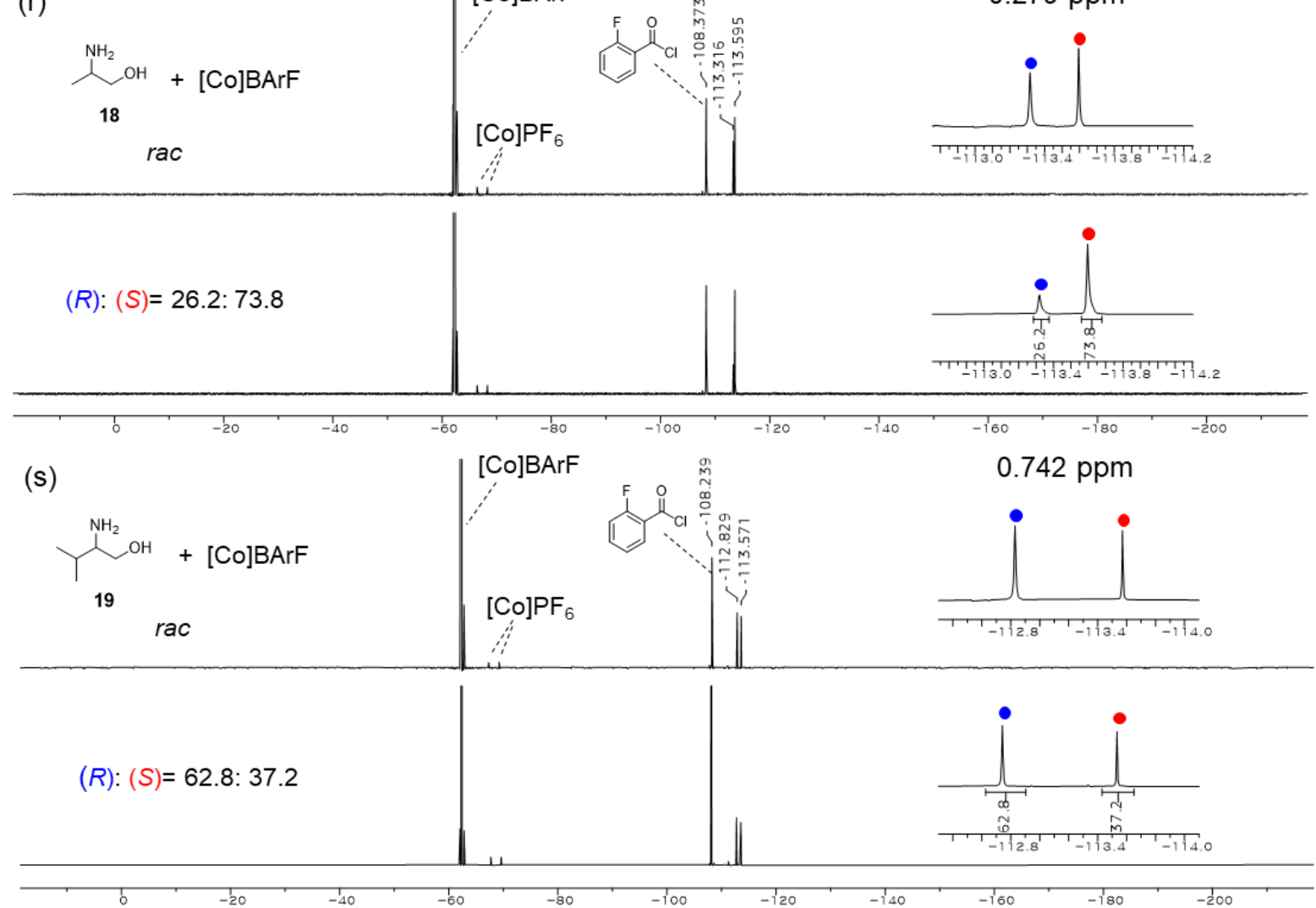

(t)
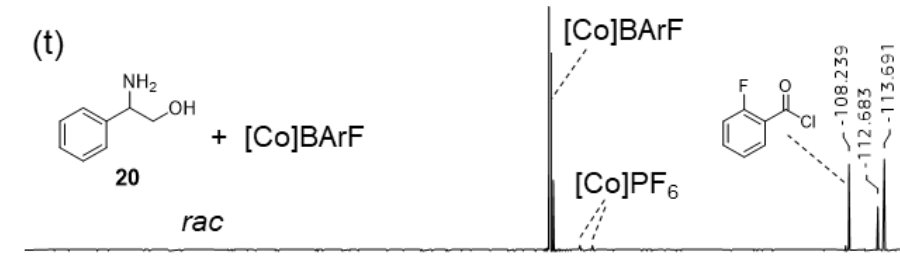

$0.742 \mathrm{ppm}$
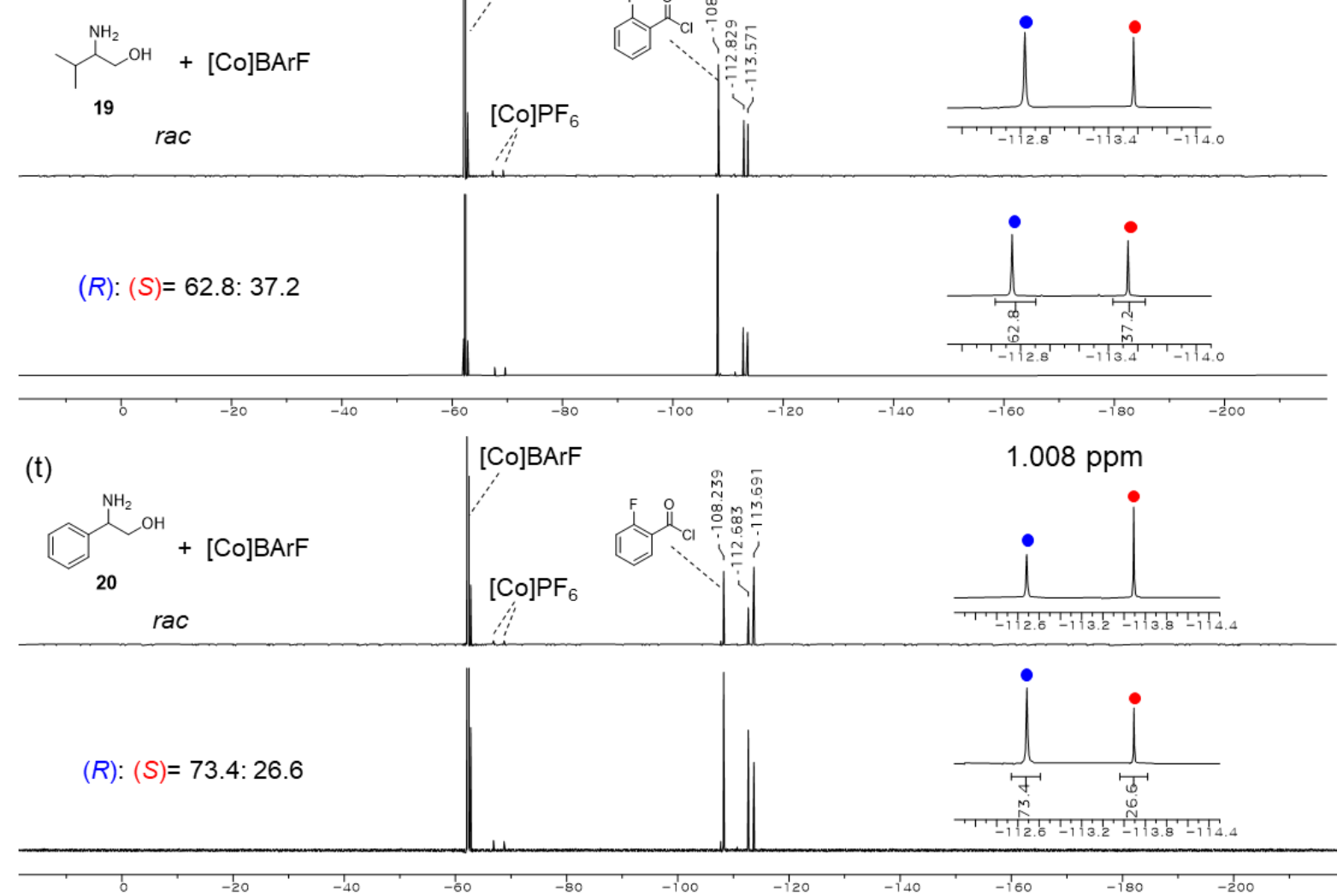


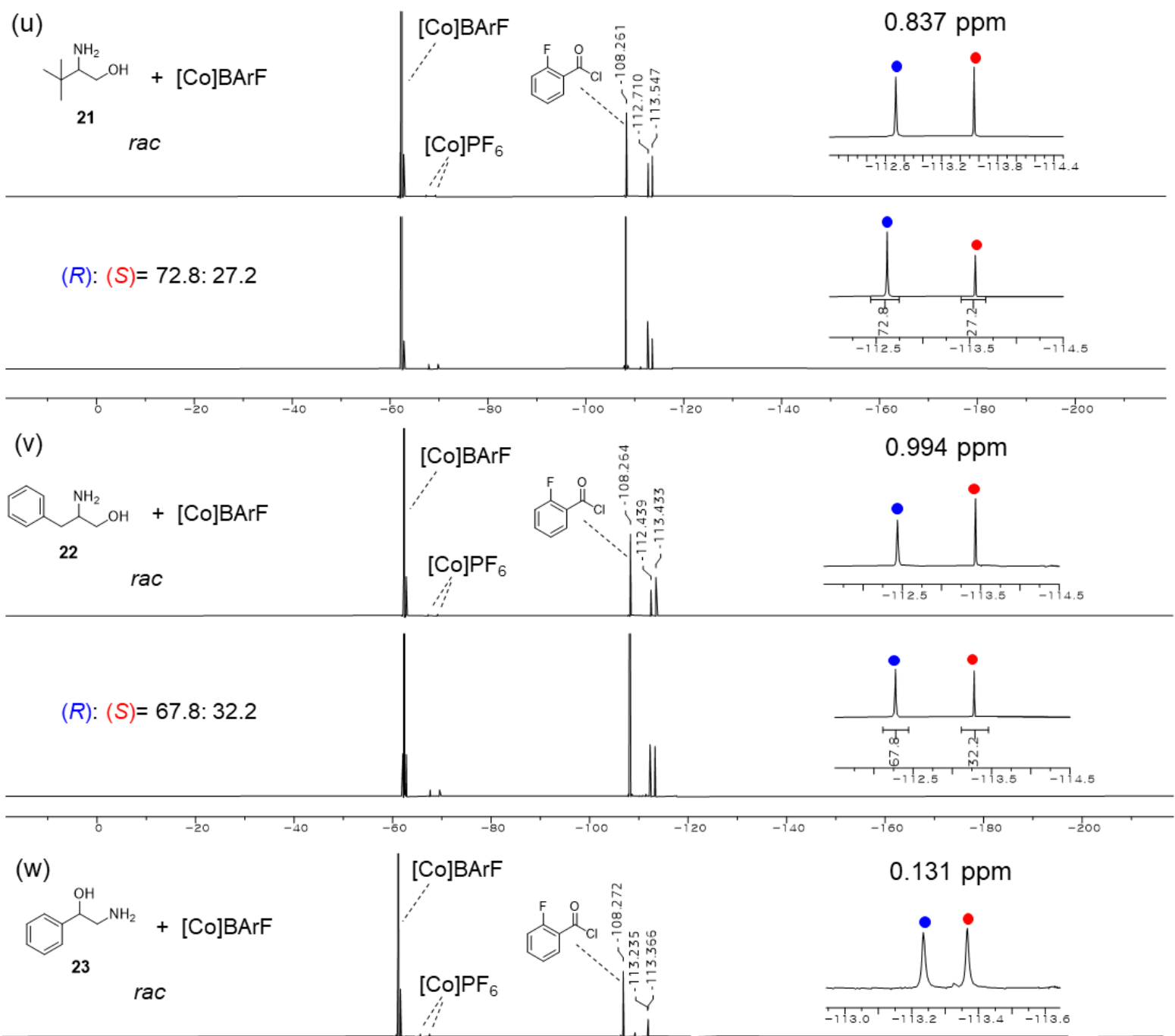

$(R):(S)=73.8: 26.2$

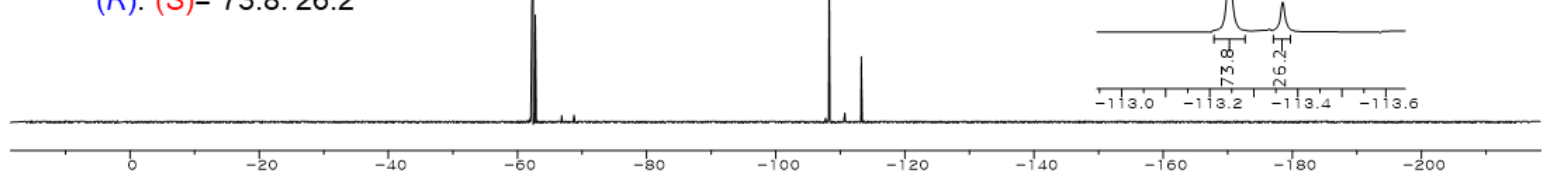

(x)
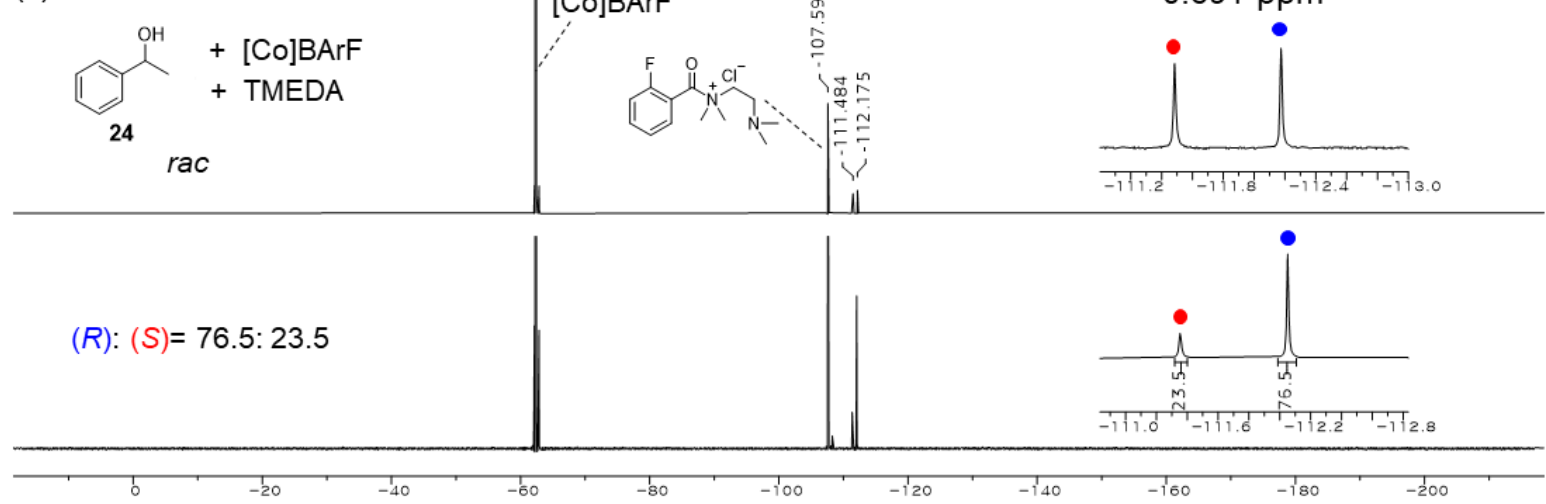


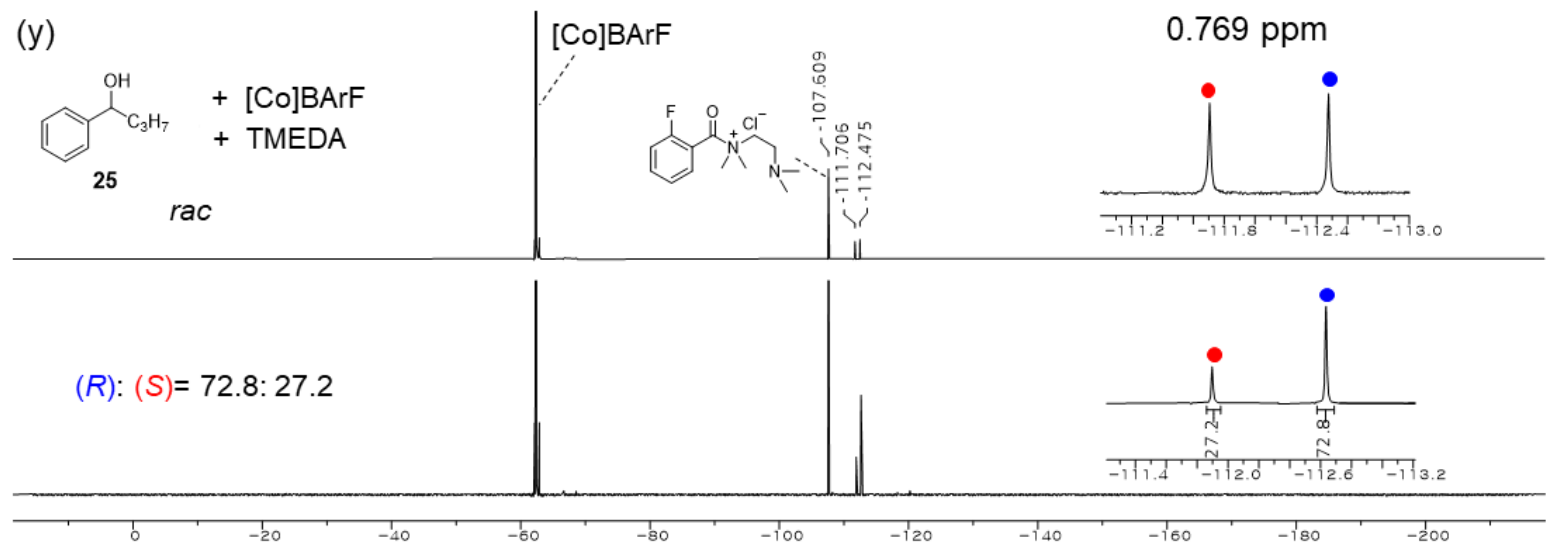

(z)
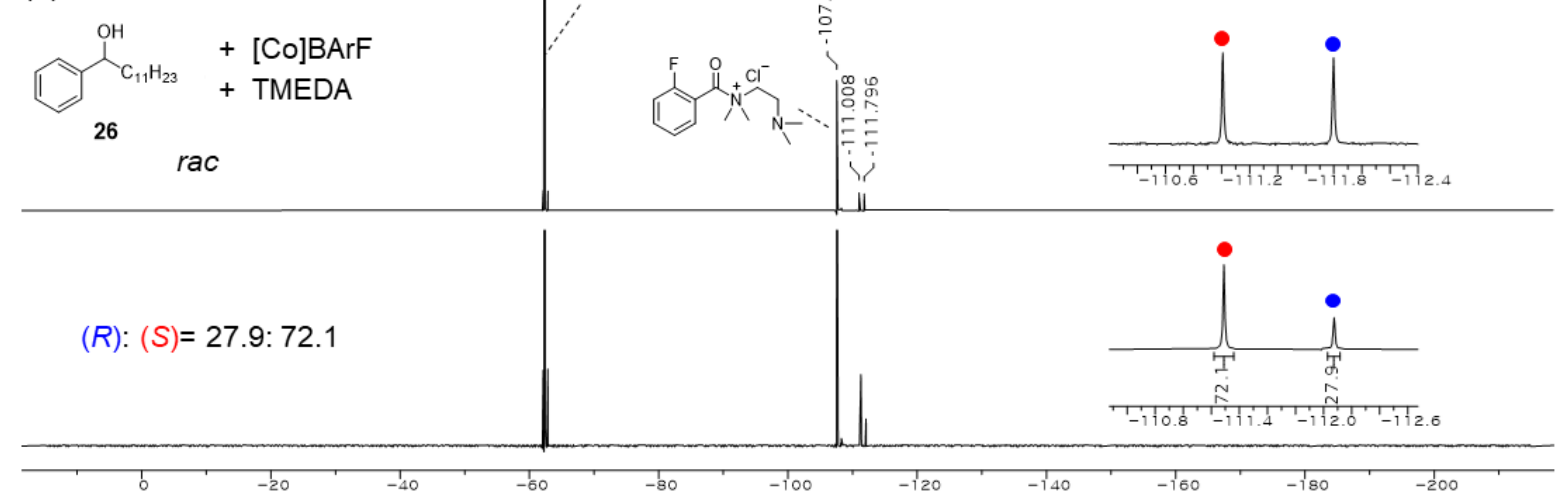

(aa)
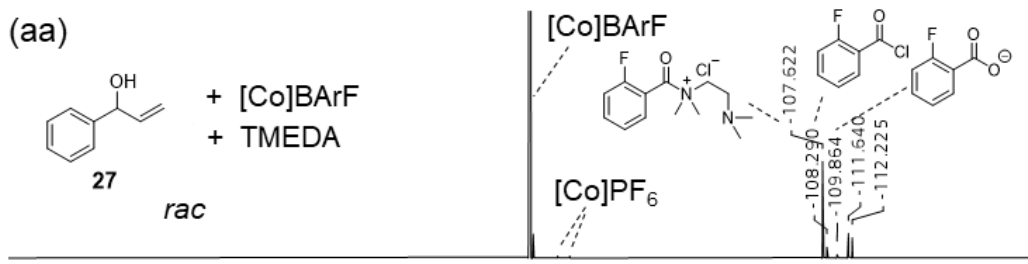

0.788 ppm
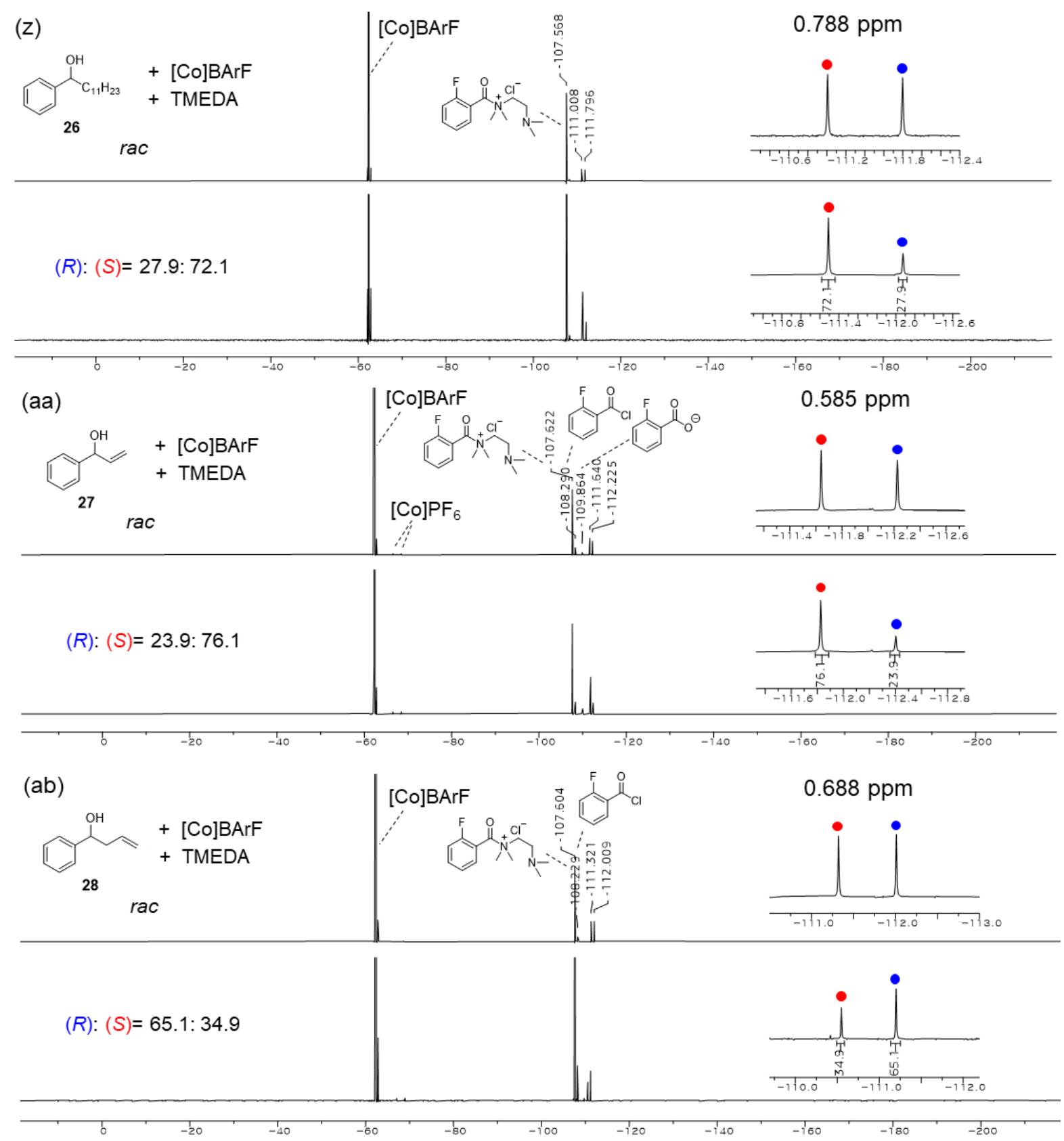
(ac)
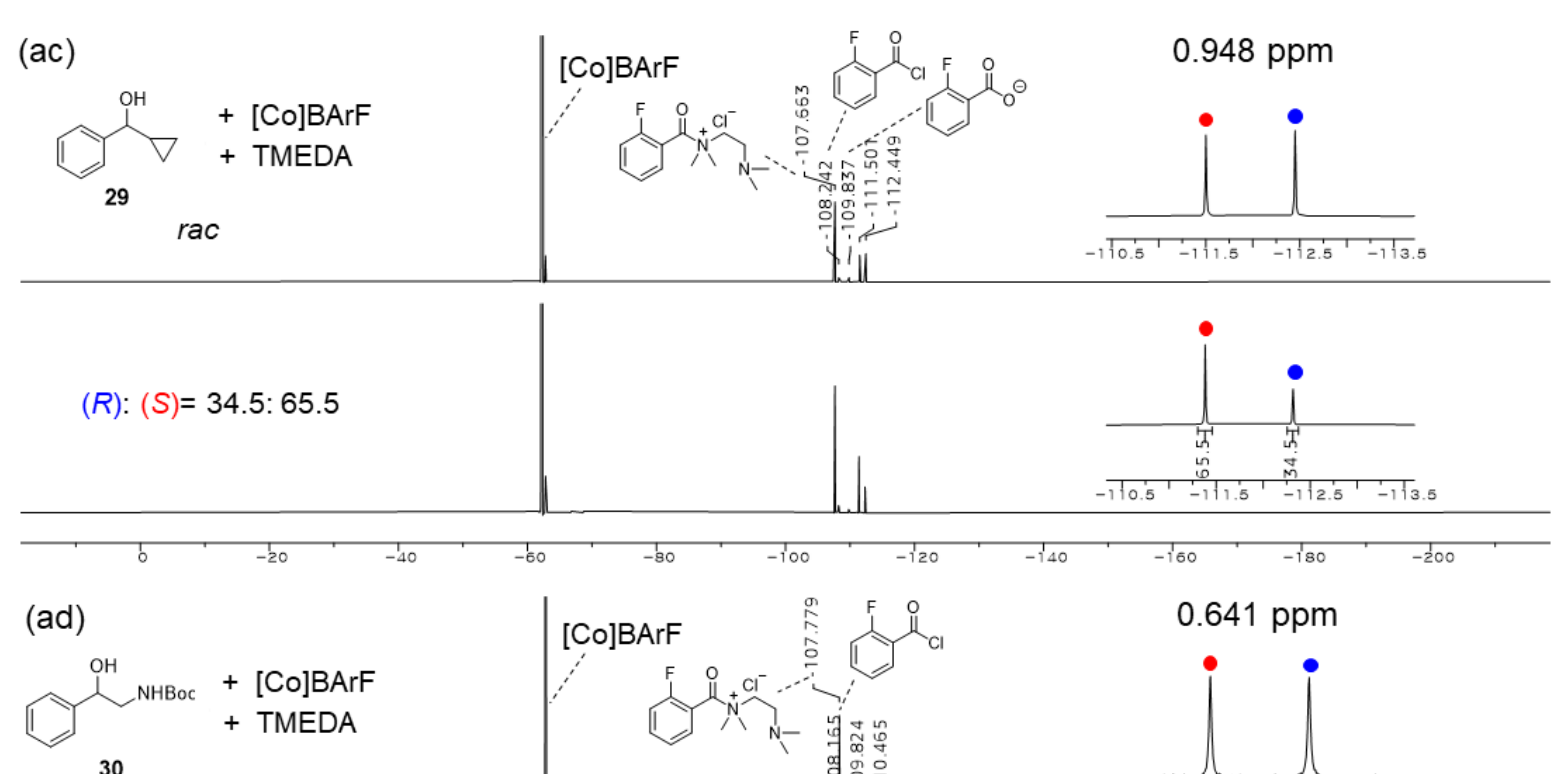

30 rac

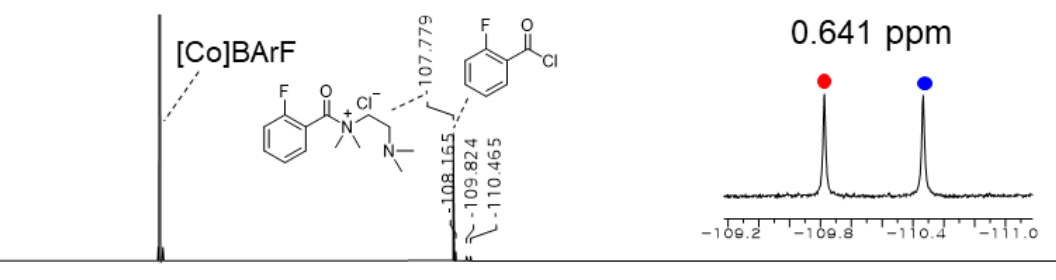

$(R):(S)=78.6: 21.4$

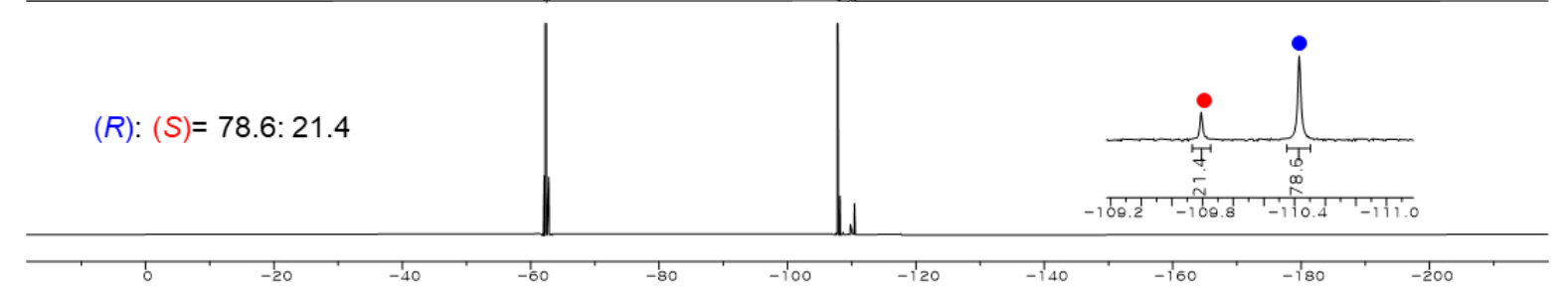

(ae)
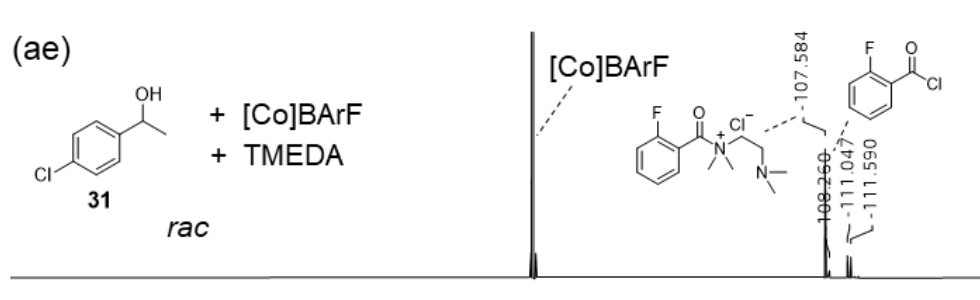

$0.543 \mathrm{ppm}$
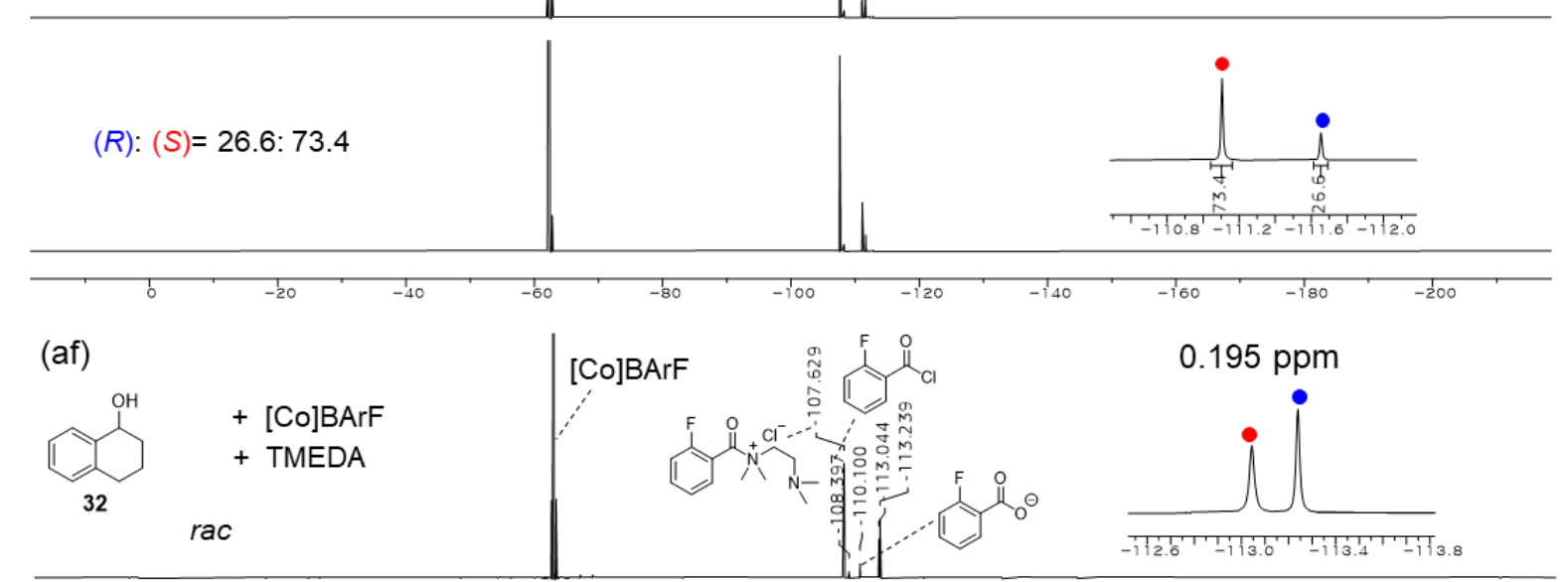

$0.195 \mathrm{ppm}$

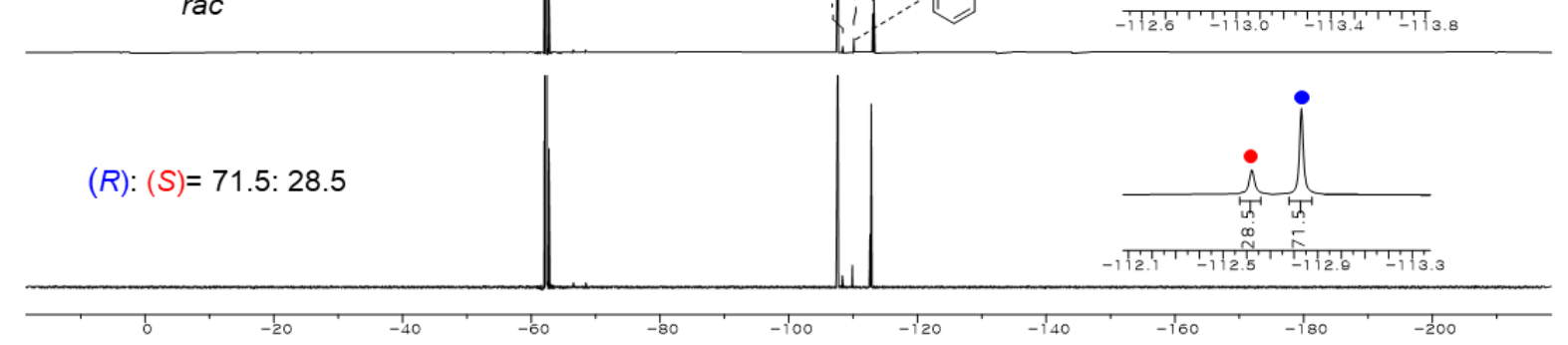




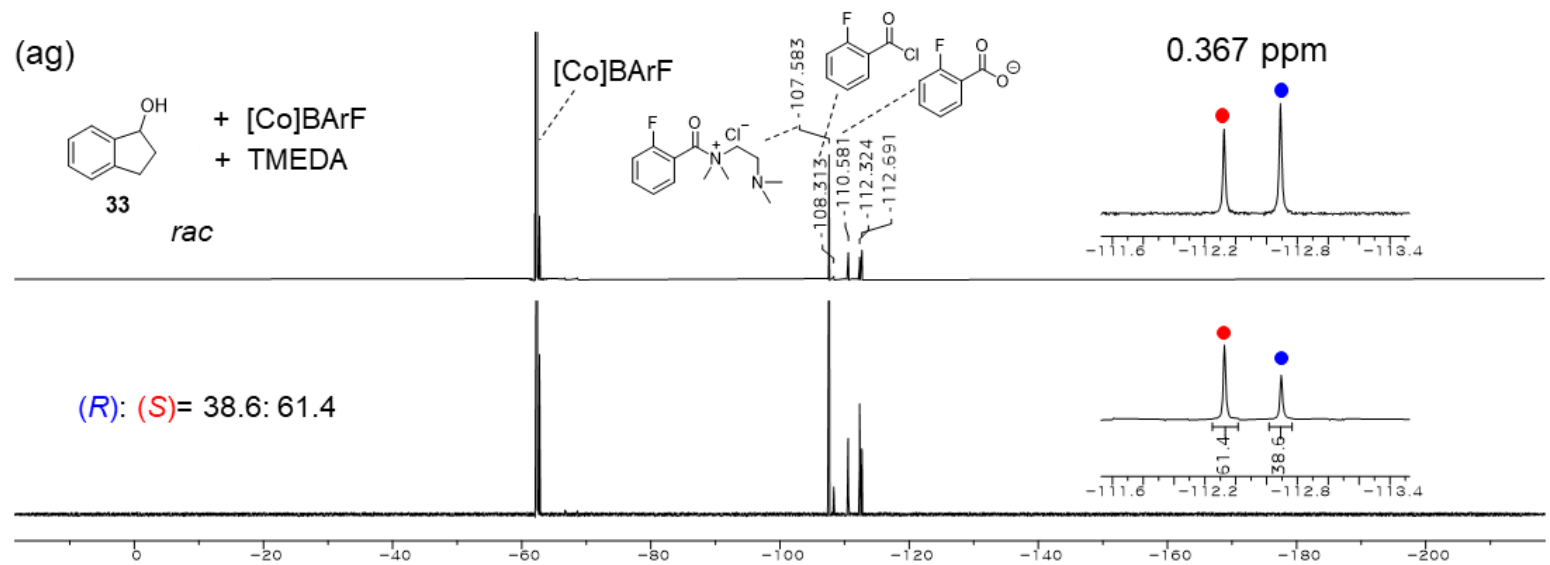

(ah)
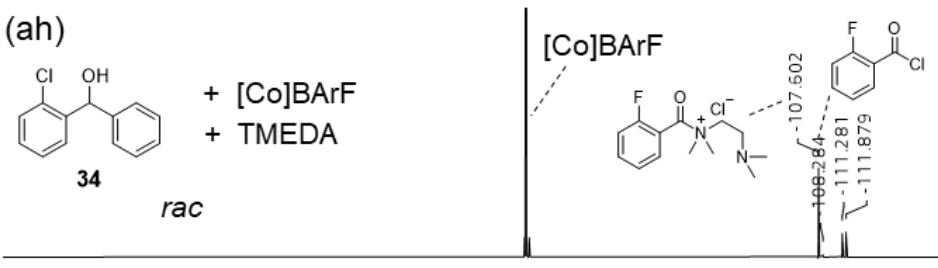

$0.598 \mathrm{ppm}$
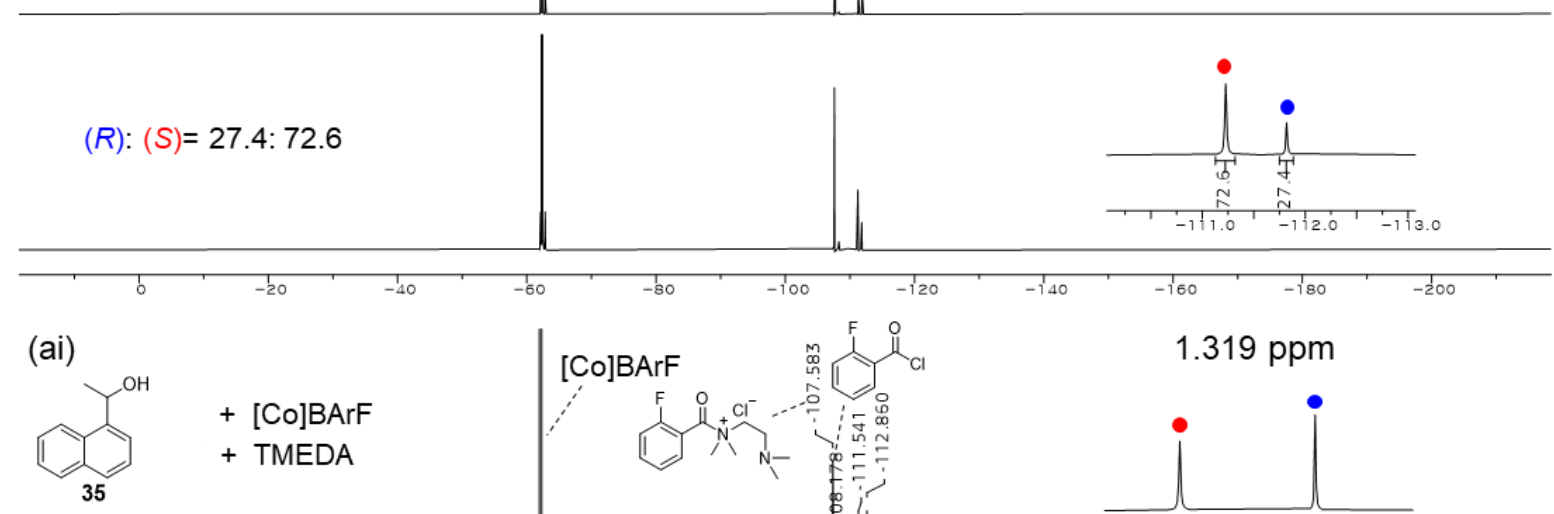

rac

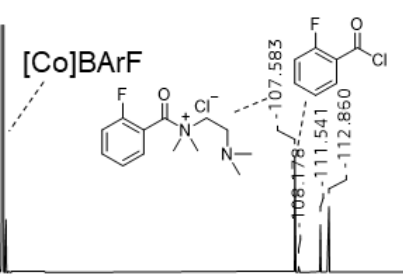

$1.319 \mathrm{ppm}$

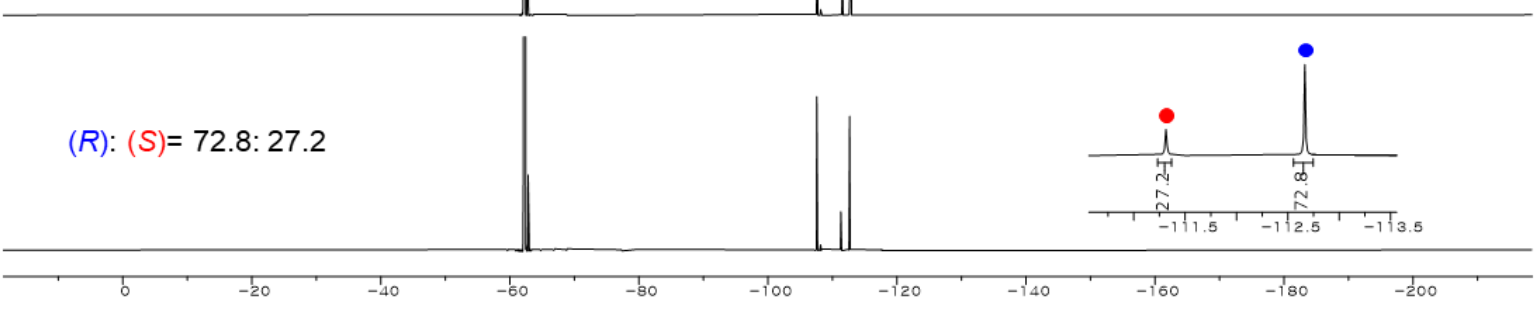

(aj)
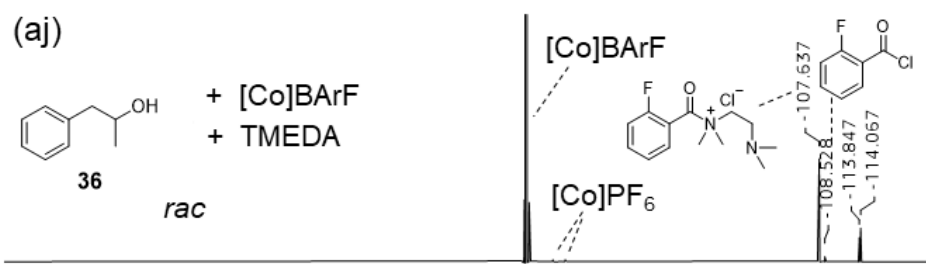

$0.220 \mathrm{ppm}$

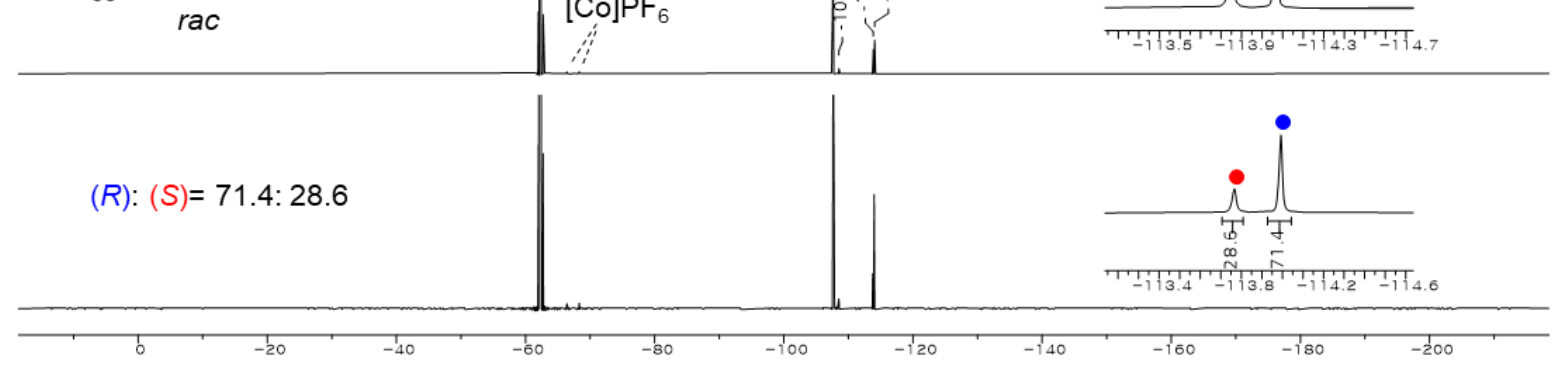



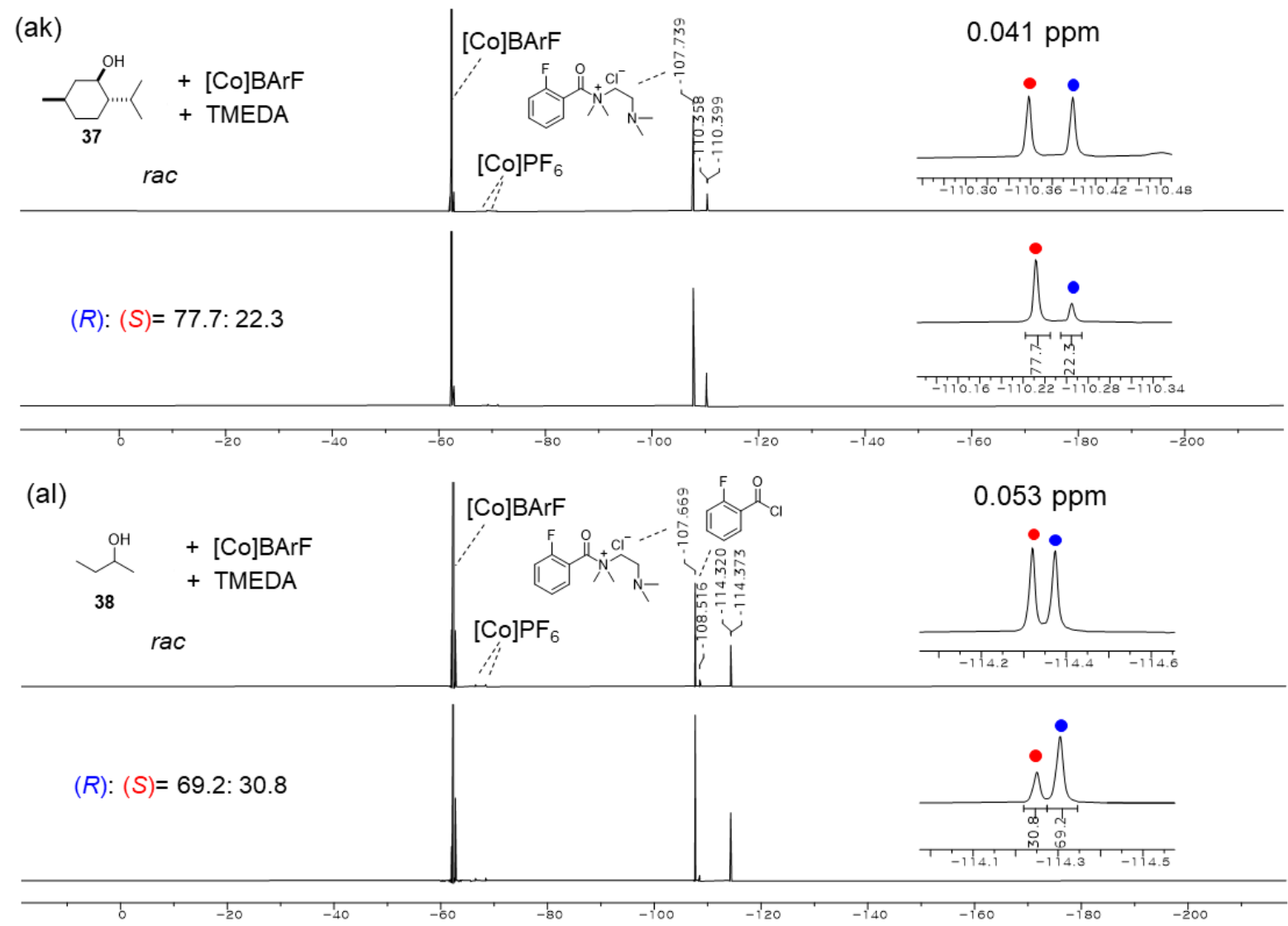

(am)

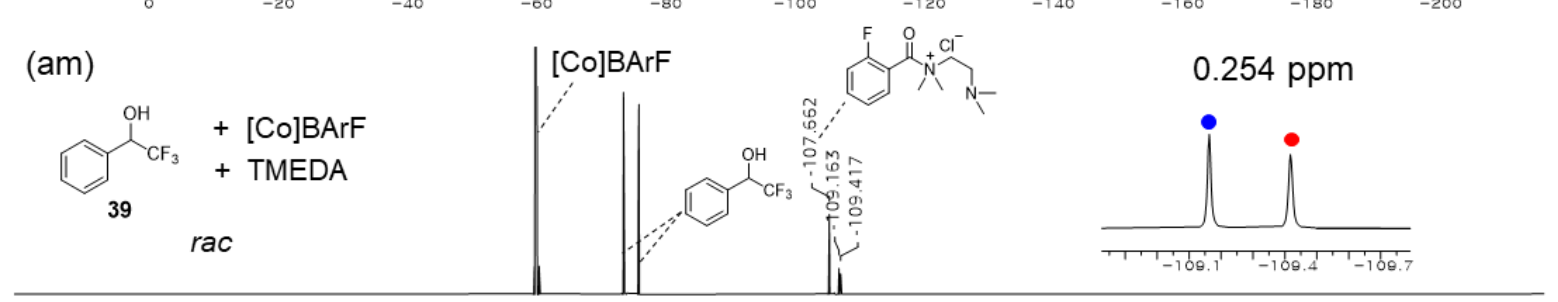

$(R):(S)=75.3: 24.7$
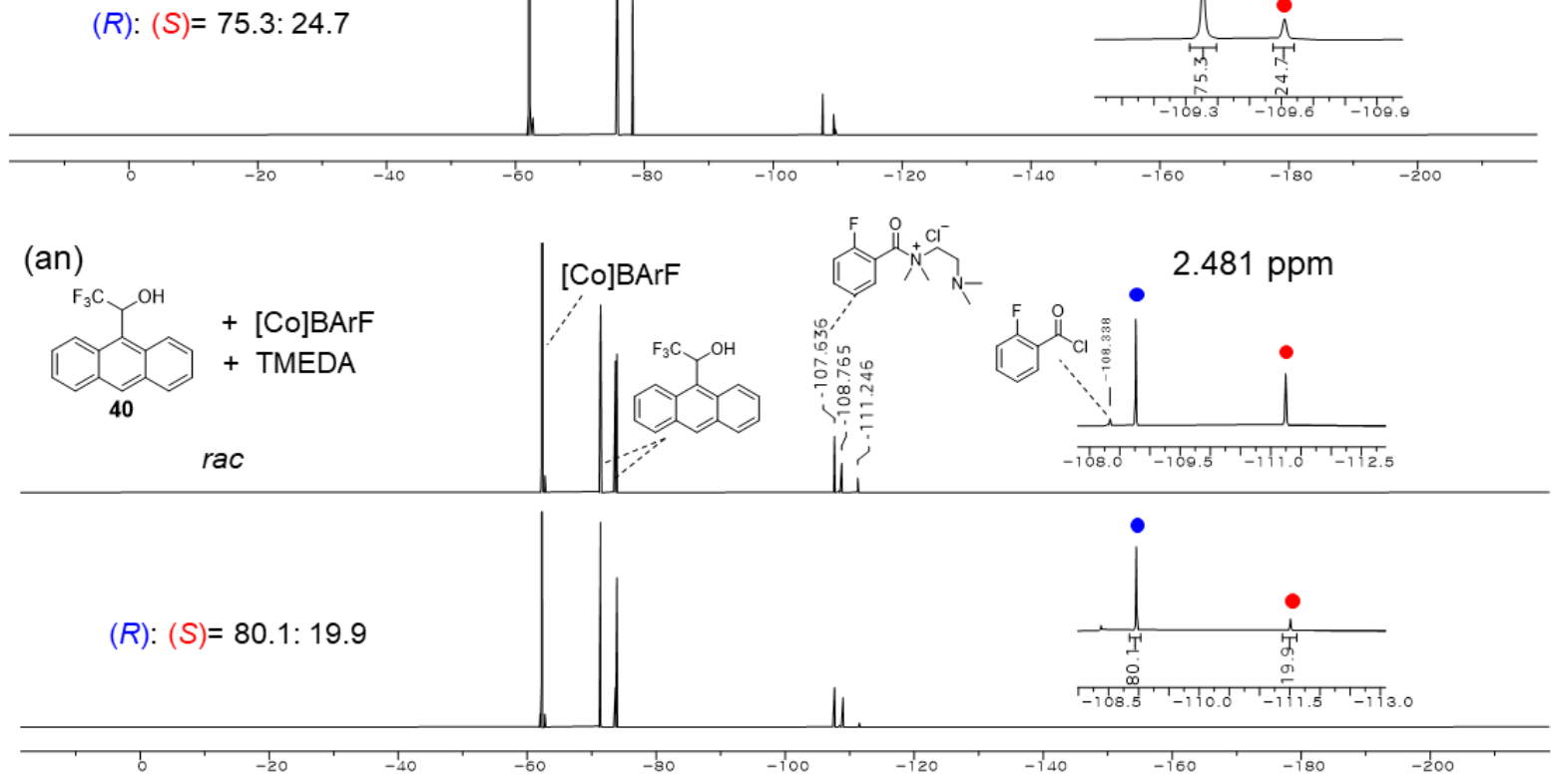


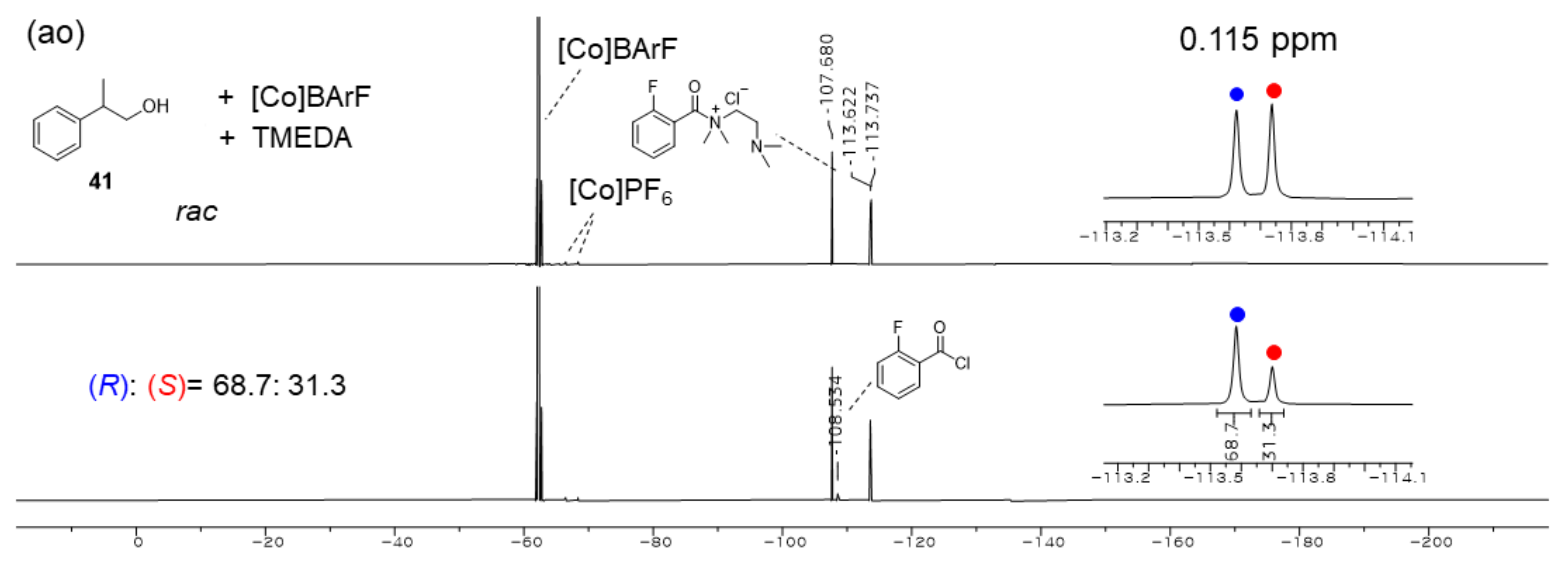

Figure S6. ${ }^{19} \mathrm{~F}\left\{{ }^{1} \mathrm{H}\right\}$ NMR spectra of 1:1 mixture of rac- or enantioenriched analyte $(22.8-61.6 \%$ ee) and [Co]BArF (ca. c = $16.7 \mathrm{mM}$ ).

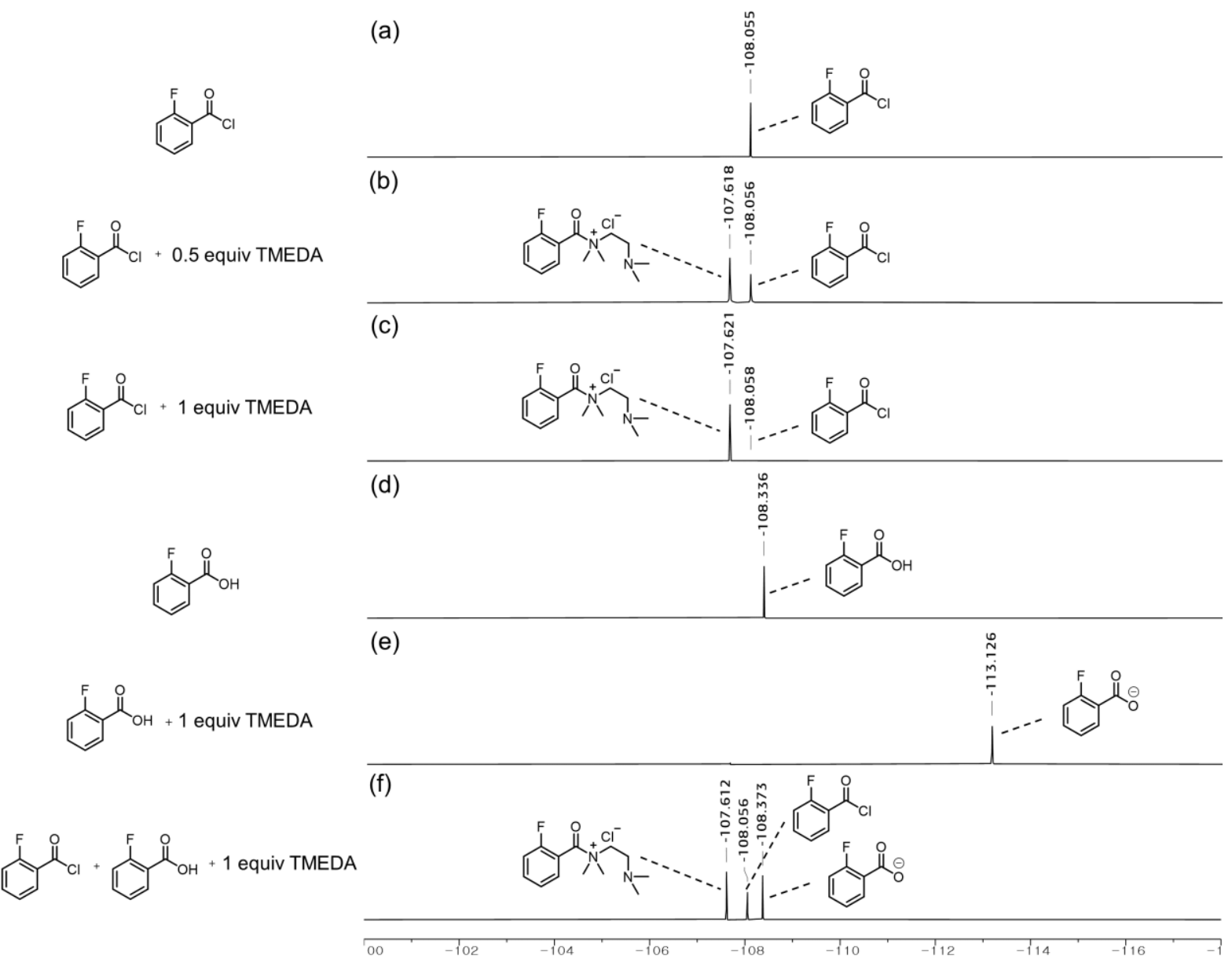

Figure S7. Identification of byproducts derived from 2-fluorobenzoyl chloride 


\section{Determination of absolute configuration}

(a)

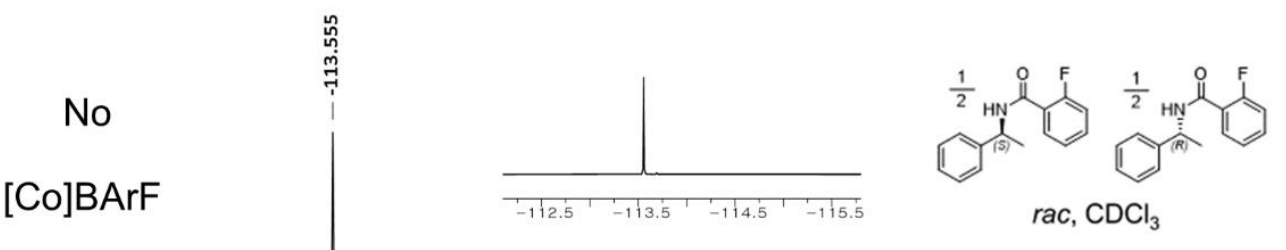

(b)

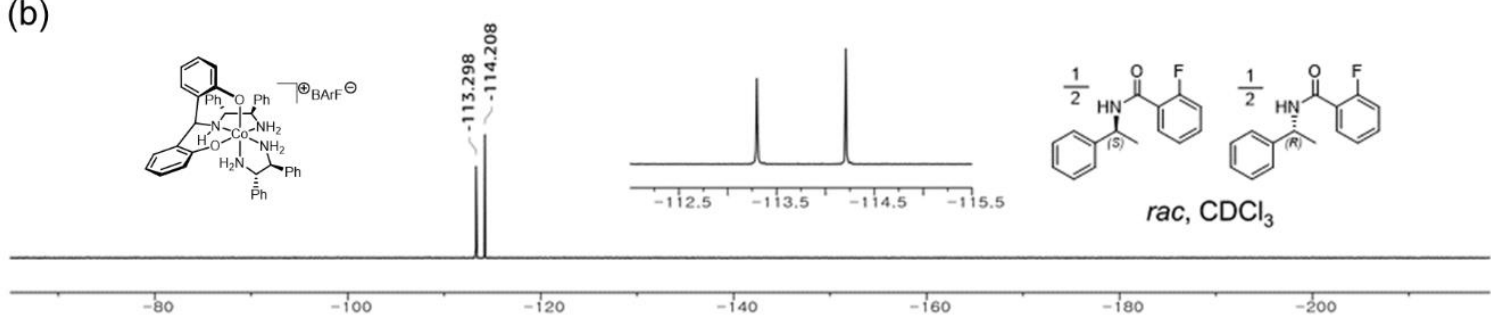

(c)

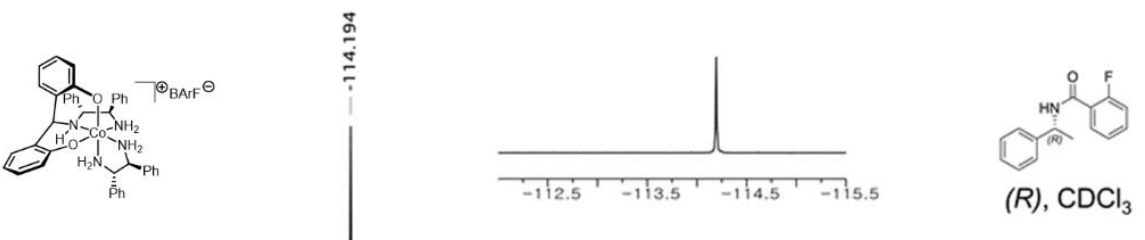

(d)
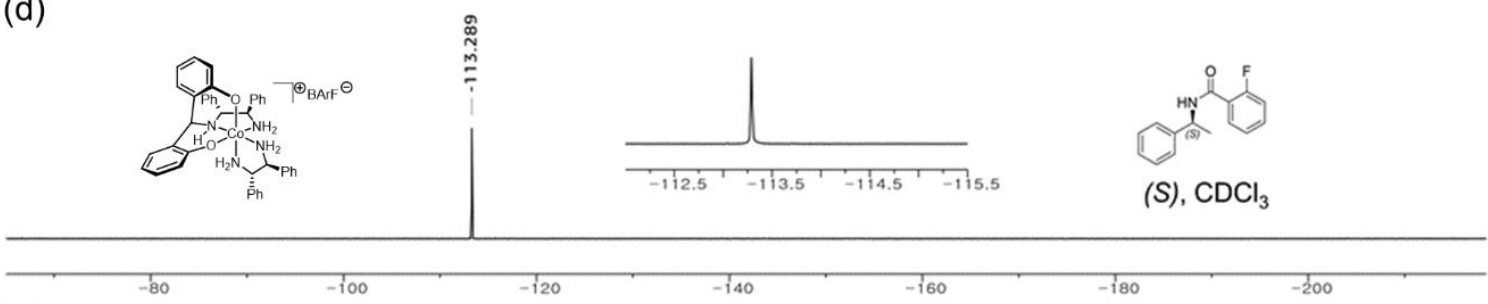

(e)

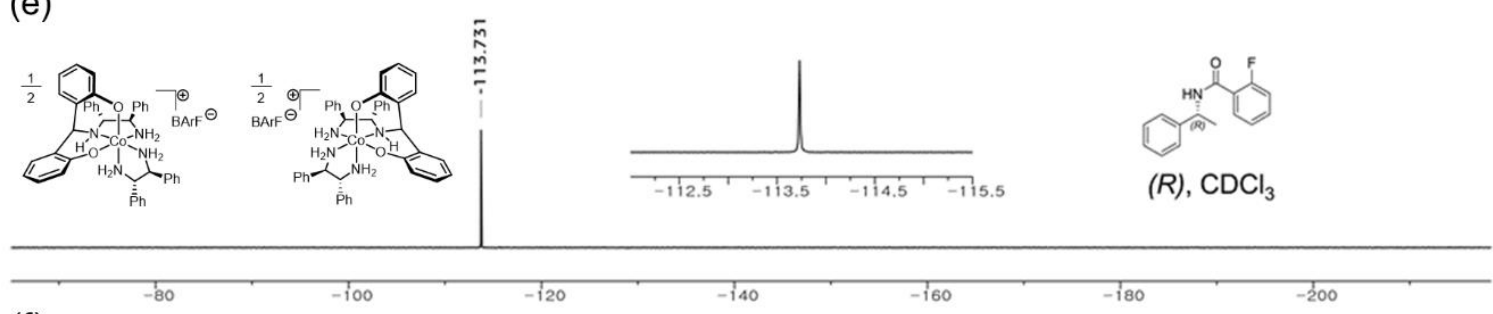

(f)

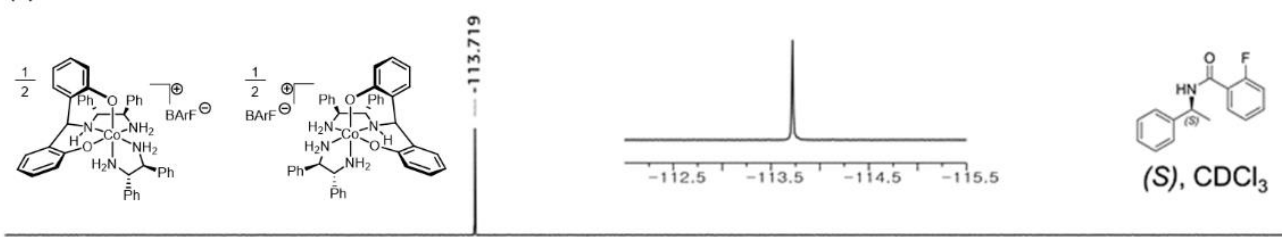

Figure S8. ${ }^{19} \mathrm{~F}\left\{{ }^{1} \mathrm{H}\right\}$ NMR spectra of 1:1 mixture of [Co]BArF and 2-fluoro- $N$-(1-phenylethyl)benzamide (ca. $\mathrm{c}=16.7 \mathrm{mM}$ ). 


\section{Analysis of L-menthol and neomenthol}

(a)
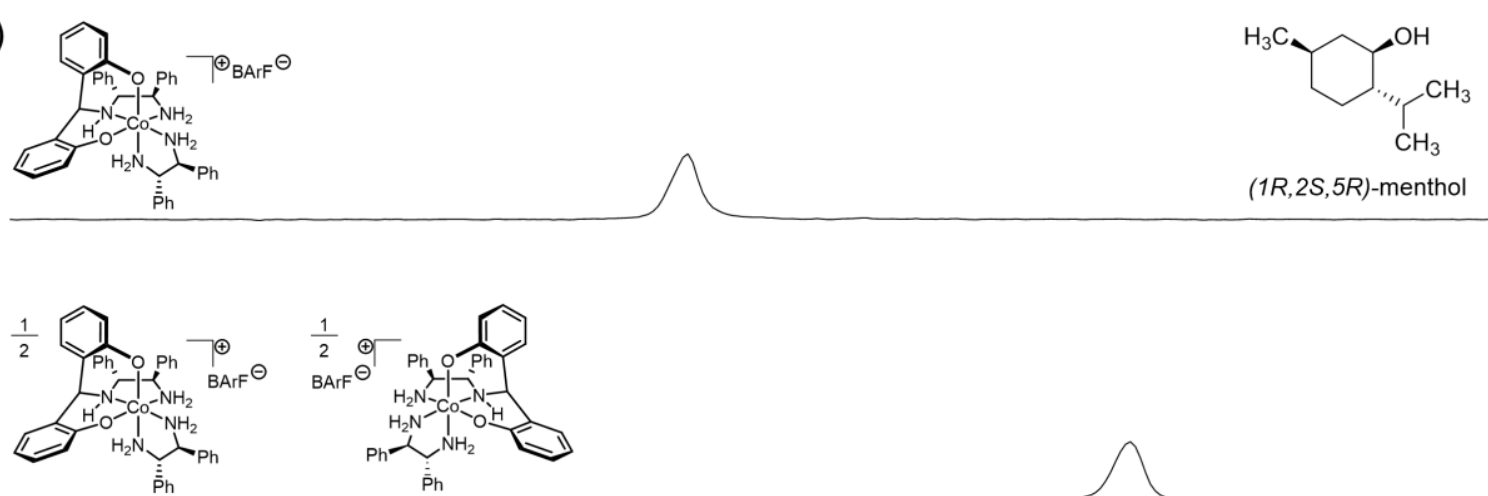

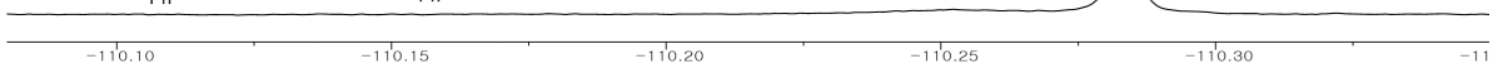

(b)
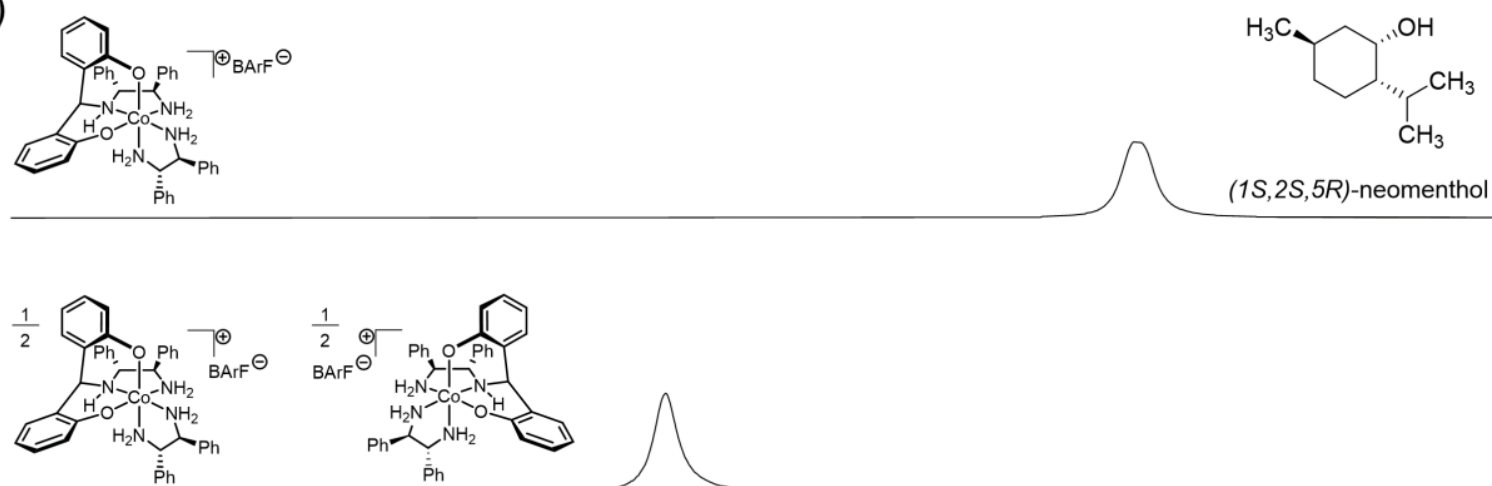

$10.8-111.0+-111.2+111.4$

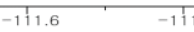

Figure S9. Partial ${ }^{19} \mathrm{~F}\left\{{ }^{1} \mathrm{H}\right\}$ NMR spectra of 1:1 mixture of $\mathrm{L}$-menthol or neomenthol and [Co]BArF or ent-[Co]BArF

\section{Fluorine-labeling with 2-fluorobenzoyl chloride or trifluoroacetyl anhydride}

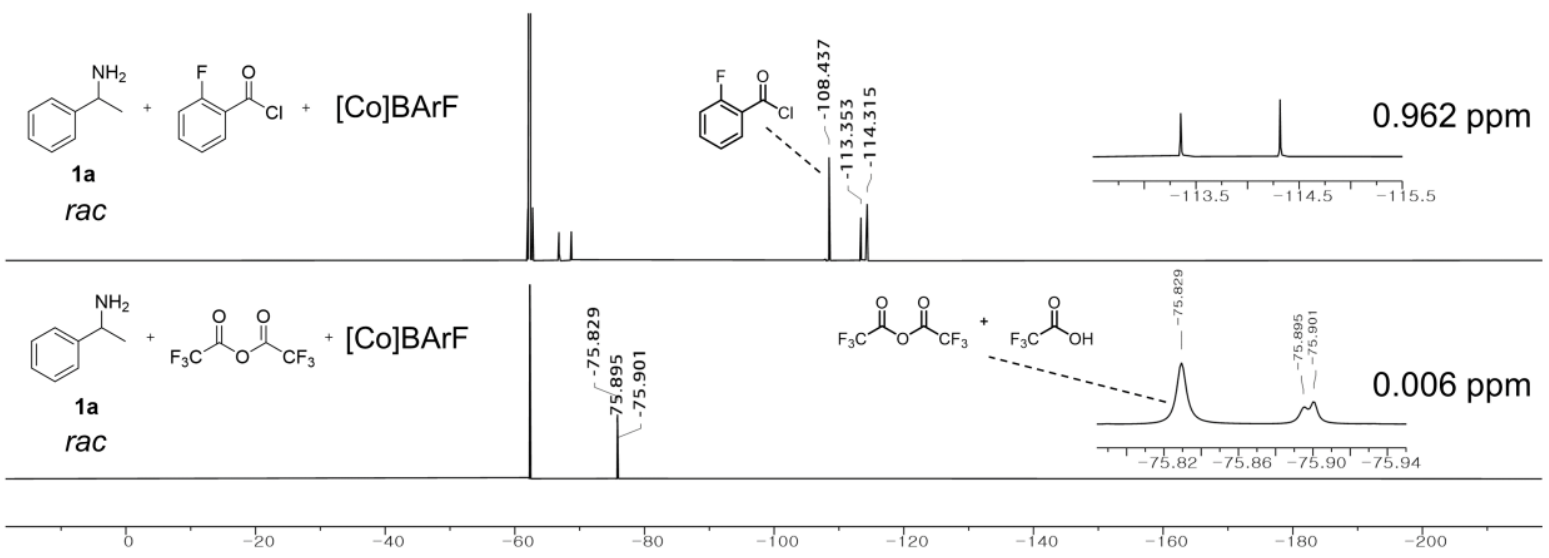

Figure S10. Chiral solvation of in-situ generated trifluoro- $N$-(1-phenylethyl)acetamide 